\title{
Changes in Characteristics of Rapidly Intensifying Western North Pacific Tropical Cyclones Related to Climate Regime Shifts
}

\author{
HAIKUN ZHAO \\ Key Laboratory of Meteorological Disaster, Ministry of Education, and Joint International Research Laboratory \\ of Climate and Environment Change, and Collaborative Innovation Center on Forecast and Evaluation of \\ Meteorological Disaster, and Pacific Typhoon Research Center, and Earth System Modeling Center, \\ Nanjing University of Information Science and Technology, Nanjing, China \\ XINGYI DUAN \\ Key Laboratory of Meteorological Disaster, Ministry of Education, Nanjing University of Information \\ Science and Technology, Nanjing, China \\ G. B. RAGA \\ Centro de Ciencias de la Atmósfera, Universidad Nacional Autónoma de México, Mexico City, Mexico \\ PHILIP J. KLOTZBACH \\ Department of Atmospheric Science, Colorado State University, Fort Collins, Colorado
}

(Manuscript received 17 January 2018, in final form 12 July 2018)

\begin{abstract}
A significant increase in the proportion of tropical cyclones undergoing rapid intensification at least once during their lifetime (RITCs) over the western North Pacific (WNP) is observed since 1998 when an abrupt climate regime shift occurred. Changes of large-scale atmospheric and oceanic conditions affecting TC activity are compared between two subperiods: one before and one since 1998. Results suggest that both a significant decrease in the number of TCs and a nearly unchanged number of RITCs since 1998 caused a significant increase in the frequency of RITCs. The decrease in TC numbers is likely driven by considerably increased vertical wind shear and decreased low-level vorticity. In contrast, the unchanged RITC counts and thus increased ratio of RITCs during the recent decades are largely attributed to the dominance of a more conducive ocean environment with increased TC heat potential and warmer sea surface temperature anomalies. These associated decadal changes are closely associated with the recent climate regime shift. During the recent decades with a mega-La Niña-like pattern, stronger easterly trade winds have caused increased vertical wind shear and a weakened monsoon trough, thus hampering TC formation ability over the WNP. In addition, a steeper thermocline slope that hampered the eastward migration of warm water along the equatorial Pacific has generated a more favorable thermodynamic environment supporting TC rapid intensification over the WNP.
\end{abstract}

\section{Introduction}

A tropical cyclone (TC) is one of the most devastating and deadly weather phenomenon on Earth, having the potential to cause significant economic damage and great loss of life (Pielke et al. 2008; Zhang et al. 2009). Accurate forecasts of TC activity play a vital role in disaster prevention and mitigation. Over the past

Corresponding author: Dr. Haikun Zhao, zhk2004y@gmail.com several decades, the prediction of TC tracks has steadily improved (Rappaport et al. 2009; DeMaria et al. 2014; Elsberry 2014), while there has been considerably less improvement in our ability to forecast TC intensity and intensity change (Elsberry et al. 2007; Rappaport et al. 2009; Chen et al. 2011; Elsberry 2014). Particularly, the rapid intensification (RI) process for a TC has long been one of the greatest challenges for operational forecasts (Rappaport et al. 2009). Therefore, advanced understanding of the underlying physical processes related 
to RI would be helpful for improving TC intensity forecast guidance and thus aiding in preparations ahead of landfall. These preparations can then consequently reduce losses caused by TCs.

The RI of a TC is largely dependent on the large-scale atmosphere-ocean environment. Efforts have been made to identify favorable environmental conditions for RI on various time scales including the synoptic scale (Kaplan and DeMaria 2003; Ventham and Wang 2007), the intraseasonal time scale (Wang and Zhou 2008; Klotzbach 2012), the seasonal time scale (Brand 1973; Holliday and Thompson 1979), the interannual time scale (Wang and Zhou 2008; Klotzbach 2012), and the decadal or interdecadal time scale (Wang et al. 2015; Wang and Liu 2016; Wang et al. 2017). Over the western North Pacific (WNP), Wang and Zhou (2008) suggested TC formation and RI share common environmental conditions on intraseasonal and interannual time scales. Similar results can be found for interdecadal time scales (Wang et al. 2015; Wang and Liu 2016). Weak vertical wind shear, a strong upper-level anticyclonic circulation, and large midlevel relative humidity were generally regarded to be favorable atmospheric factors for the RI process. Warm sea surface temperatures (SSTs) and large upper-ocean heat content are known to be two positive oceanic factors for the RI process. Particularly, the upper-ocean heat content is a well-documented critical factor for RI, with a general consensus that TCs are likely to undergo RI when they form and develop over a region with large upper-ocean heat content (Emanuel 1986, 1999; Bender and Ginis 2000; Shay et al. 2000; Goni and Trinanes 2003; Lin et al. 2005, 2008, 2011; Black et al. 2007; Mainelli et al. 2008; Goni et al. 2009; D'Asaro et al. 2011; Pun et al. 2011).

Over the past two decades, considerable attention has been placed on how climate change affects TC activity (Emanuel 2005; Webster et al. 2005; Knutson et al. 2010). On the interdecadal time scale, it is well known that the Pacific basin SST experienced a climate regime shift around the late 1970s (Miller et al. 1994; Wang 1995), leading to significant circulation changes over many regions of the globe (Chang et al. 2000a,b; Zhou et al. 2009). Recent studies suggested that the tropical climate experienced another abrupt regime shift around 1998 (McPhaden et al. 2011; Hong et al. 2014). Correspondingly, a significant decrease in WNP TC frequency was observed since the late 1990s (Maue 2011; Liu and Chan 2013; Hsu et al. 2014; Hong et al. 2016; Zhao and Wang 2016, 2018). Also, a pronounced northwestward shift of TC genesis location occurred around that time (Wu et al. 2015; Zhao and Wang 2016; C. D. Hu et al. 2018). These changes in
WNP TC activity are consistent with decadal changes in large-scale phenomena [e.g., the tropical uppertropospheric trough (TUTT) and the monsoon trough] and changes in environmental factors affecting TC activity (Liu and Chan 2013; Hsu et al. 2014; Wu et al. 2015; He et al. 2017; C. D. Hu et al. 2018; Huangfu et al.2017). For example, over the WNP, TCs often occur to the west of the TUTT (Wu et al. 2015), mostly over the main development region, as a result of the strong vertical wind shear to the southeast of the trough (e.g., Kelley and Mock 1982; Fitzpatrick et al. 1995). Studies suggested that these associated changes were due to the synergy effect of the tropical Pacific climate shift since 1998 (Liu and Chan 2013; Hsu et al. 2014; Zhao and Wang 2016; C. D. Hu et al. 2018). Recent studies (Webster et al. 2005; Chan 2008; Wu and Wang 2008; Zhan et al. 2017) have suggested that the number of major TCs over the WNP and its percentage have shown an increasing trend over the past three decades.

Wang and Zhou (2008) pointed out that most typhoons over the WNP basin undergo at least one period of RI; about $90 \%$ of category 4 and 5 TCs in the WNP experience at least one RI process during their life cycle. Wang et al. (2015) suggested that RI events over the WNP basin exhibit strong interdecadal variability and further pointed out that interdecadal variation of RI events are strongly associated with changes of largescale factors modulated by the phase transition of the Pacific decadal oscillation (PDO). However, the proportion of rapid intensification of tropical cyclones (RITCs) over the WNP basin has been relatively less studied.

Details of how the spatiotemporal distribution of TC intensity may change in response to climate change remains uncertain (Knutson et al. 2010; Soloviev et al. 2014; Emanuel 2017). The projection of the most intense TCs or of the RI process in the context of climate change is notoriously difficult to simulate. Lee et al. (2016) demonstrated that RI plays a crucial role not only in weather forecasting but also in TC climatology. A better understanding of RI in the current climate therefore is necessary for exploring the fundamental physical mechanism or mechanisms responsible for TC variability in a changing climate. Together with the recent abrupt climate regime shift in 1998, two interesting questions arise: Does the proportion of RITCs over the WNP basin change between pre- and post-1998? If yes, what is the possible mechanism responsible for the change of proportion of RITCs over the WNP since 1998? This study is an attempt to answer these two questions, primarily focusing on the potential impacts of the recent climate 
regime shift in 1998 with specific emphasis on exploratory analyses.

The rest of this study is arranged as follows. The data and methodology, as well as the techniques used to identify RITC are introduced in section 2. Section 3 presents the statistical characteristics of TCs, RITCs, and proportion of RITCs over the WNP basin. Section 4 compares the changes of large-scale atmospheric and oceanic factors between two subperiods: the first subperiod is 1979-97 (P1) and the second subperiod is 19982015 (P2). The hypothesized physical mechanisms driven by the recent climate regime shift and how they impact the proportion of RITCs are explored in section 5, followed by a summary in section 6 .

\section{Data and methodology}

\section{a. TC data}

TC data from 1979 to 2015 from the Joint Typhoon Warning Center (JTWC) best track dataset (Chu et al. 2002) was used for this study. It consists of 6-hourly positions including latitude and longitude and maximum sustained wind speed. The starting year was chosen to be 1979 when both the Dvorak intensity technique estimating TC intensity and satellites monitoring TC activity became routine. In this study, we focus on TCs that are at least of tropical storm (1-min sustained winds $\geq 34 \mathrm{kt}$; $\left.1 \mathrm{kt}=0.51 \mathrm{~m} \mathrm{~s}^{-1}\right)$ intensity.

$\mathrm{Wu}$ and Zhao (2012) suggested that TC intensity records from the JTWC are relatively more reliable than other best track datasets. Several studies have pointed out discrepancies in TC intensity records among various best track datasets, mainly due to the changes in estimation techniques and computational approaches among different agencies (Emanuel 2005; Wu and Zhao 2012; Song et al. 2010). Following Emanuel et al. (2006), Wu and Zhao (2012) dynamically derived TC intensity records along all TC tracks from three best track datasets [i.e., JTWC, the Shanghai Typhoon Institute of China Meteorological Administration (CMA_STI), and the Japan Meteorological Agency (JMA)] and found better consistency in basinwide TC intensity records between simulations and observations for the JTWC in terms of various TC intensity metrics. For completeness, we also have verified the results from the JTWC by using the TC datasets from the JMA and CMA, also finding a consistent increased ratio of RITCs over the WNP basin. We caution that the results of this manuscript may be influenced by uncertainty in the TC intensity record.

In this study, we focus on the potential impacts of the recent climate regime shift in 1998 on TC activity over the WNP basin and the underlying circulation changes
(McPhaden et al. 2011; Xiang et al. 2013; Hong et al. 2014).

\section{b. Definition of a tropical cyclone undergoing RI}

TC intensity records from the JTWC are used to identify periods of RI in this study. An intensity change threshold of $30 \mathrm{kt}$ in $24 \mathrm{~h}$ is employed to define RI for all TCs over the WNP basin. Such a threshold is equivalent to about the 95th percentile of overwater intensity changes in $24 \mathrm{~h}$, which was adopted for defining RI in previous studies (Kaplan and DeMaria 2003; Wang and Zhou 2008; Kaplan et al. 2010; Wang et al. 2015; Wang and Liu 2016). Following Wang and Zhou (2008), to further avoid ambiguity in determining the onset and duration of the RI process, RI was defined in this study as satisfying the following three criteria: (i) an increase of at least $5 \mathrm{kt}$ in TC intensity in the first $6 \mathrm{~h}$, (ii) an increase of at least $10 \mathrm{kt}$ in TC intensity in the first $12 \mathrm{~h}$, and (iii) an increase of at least $30 \mathrm{kt}$ in $\mathrm{TC}$ intensity in $24 \mathrm{~h}$. We focus on each TC undergoing RI (hereafter RITC) at least once during its life cycle. The proportion of RITCs over the WNP is computed as the percentage of RITC counts to total TC counts. According to this definition, 389 RITCs out of the total of 949 TCs are identified from 1979 to 2015 over the WNP basin. In other words, about $41 \%$ of all TCs over the WNP basin underwent RI at least once during our study period, consistent with results from previous studies (Wang and Zhou 2008; Wang et al. 2015; Wang and Liu 2016).

Both monthly RITC frequency and TC counts over the WNP basin during 1979-2015 show a marked seasonal cycle (Fig. 1a). The climatologically active part of the TC season from July to November (JASON) is easily identified. During JASON, about $78 \%$ and $81 \%$ of annual total TC counts and RITC counts are observed, respectively. As displayed in Fig. 1b, RITCs during JASON tend to be concentrated in a region delimited by $10^{\circ}-22^{\circ} \mathrm{N}, 120^{\circ}-155^{\circ} \mathrm{E}$. About $60 \%$ of all RITCs can be found in this core region, characterized by relatively high low-level relative vorticity and relatively weak vertical wind shear associated with the monsoon trough, corresponding well with the main development region for TC formation. In the following sections, we mainly focus our analyses over the active season JASON during the whole period 1979-2015 and the two subperiods 1979-1997 and 1998-2015, unless otherwise specified.

\section{c. Atmospheric fields, SST, and TCHP}

Monthly mean wind from 1979 to 2015 were obtained from the National Centers for Environmental PredictionDepartment of Energy (NCEP-DOE) AMIP-II Reanalysis products (Kanamitsu et al. 2002), which has a horizontal resolution of $2.5^{\circ} \times 2.5^{\circ}$ in longitude and 

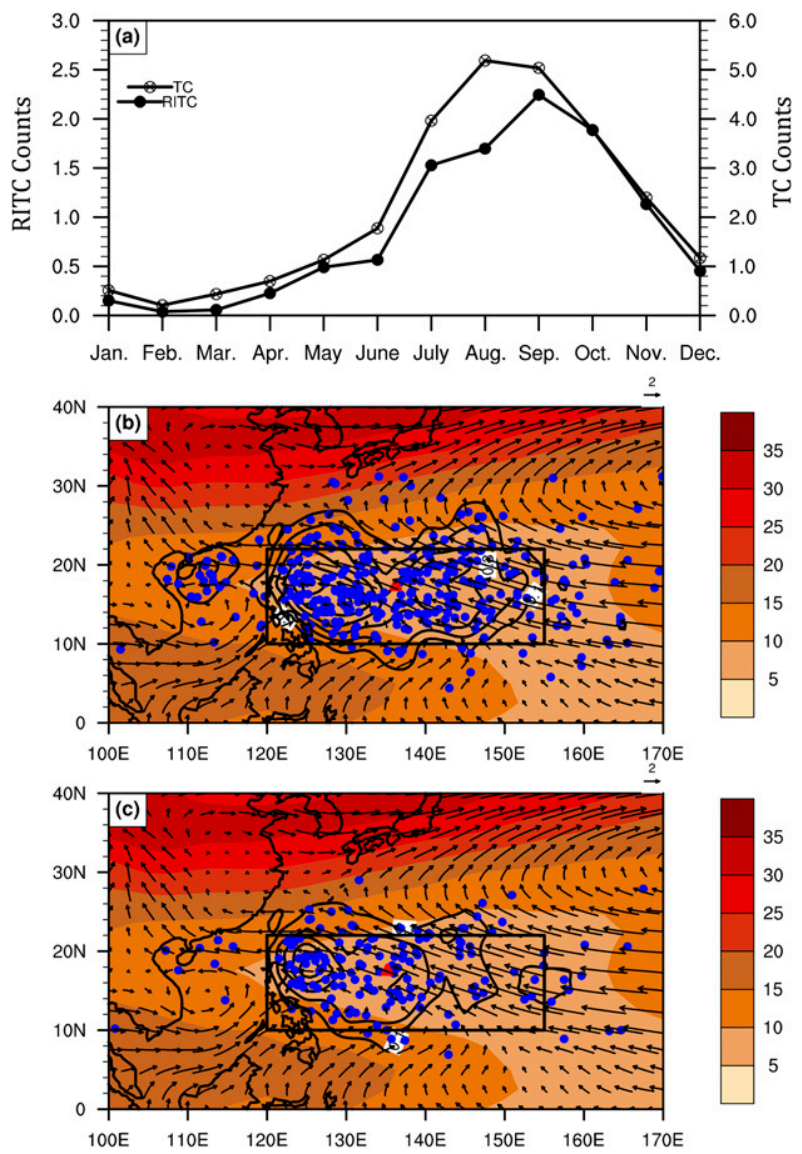

FIG. 1. (a) Monthly frequency of TCs and RITCs over the WNP basin during 1979-2015 and (b) climatological distribution of averaged $850-\mathrm{hPa}$ winds and vertical wind shear over July-November during 1979-2015 together with the first position for all RITCs (blue dots). (c) As in (b), but for a $42 \mathrm{mb} d a y^{-1}$ threshold for RI from Holliday and Thompson (1979). The rectangular box $\left(10^{\circ}-22^{\circ} \mathrm{N}\right.$, $120^{\circ}-155^{\circ} \mathrm{E}$ ) in (b) and (c) indicates the main RI region.

latitude. The vertical wind shear in this study was calculated as the magnitude of wind vector differences between 850 and $200 \mathrm{hPa}$. The SST dataset was obtained from the Extended Reconstruction SST, version 3b (ERSST v3b) (Smith et al. 2008), which has a horizontal resolution of $2.0^{\circ} \times 2.0^{\circ}$ in longitude and latitude.

Tropical cyclone heat potential (TCHP) represents the ocean heat content contained in the water warmer than $26^{\circ} \mathrm{C}$, which has been shown to be important for TC intensification (DeMaria et al. 2005; Oey et al. 2007; Wang et al. 2015; Wang and Liu 2016; Wang et al. 2017). In this study, the TCHP is used to examine the impact of upperocean conditions on RITCs. Following Leipper (1967) and Guo and Tan (2018), the TCHP is calculated as follows:

$$
\mathrm{TCHP}=C_{p} \rho \int_{D_{26}}^{0}[T(z)-26] d z,
$$
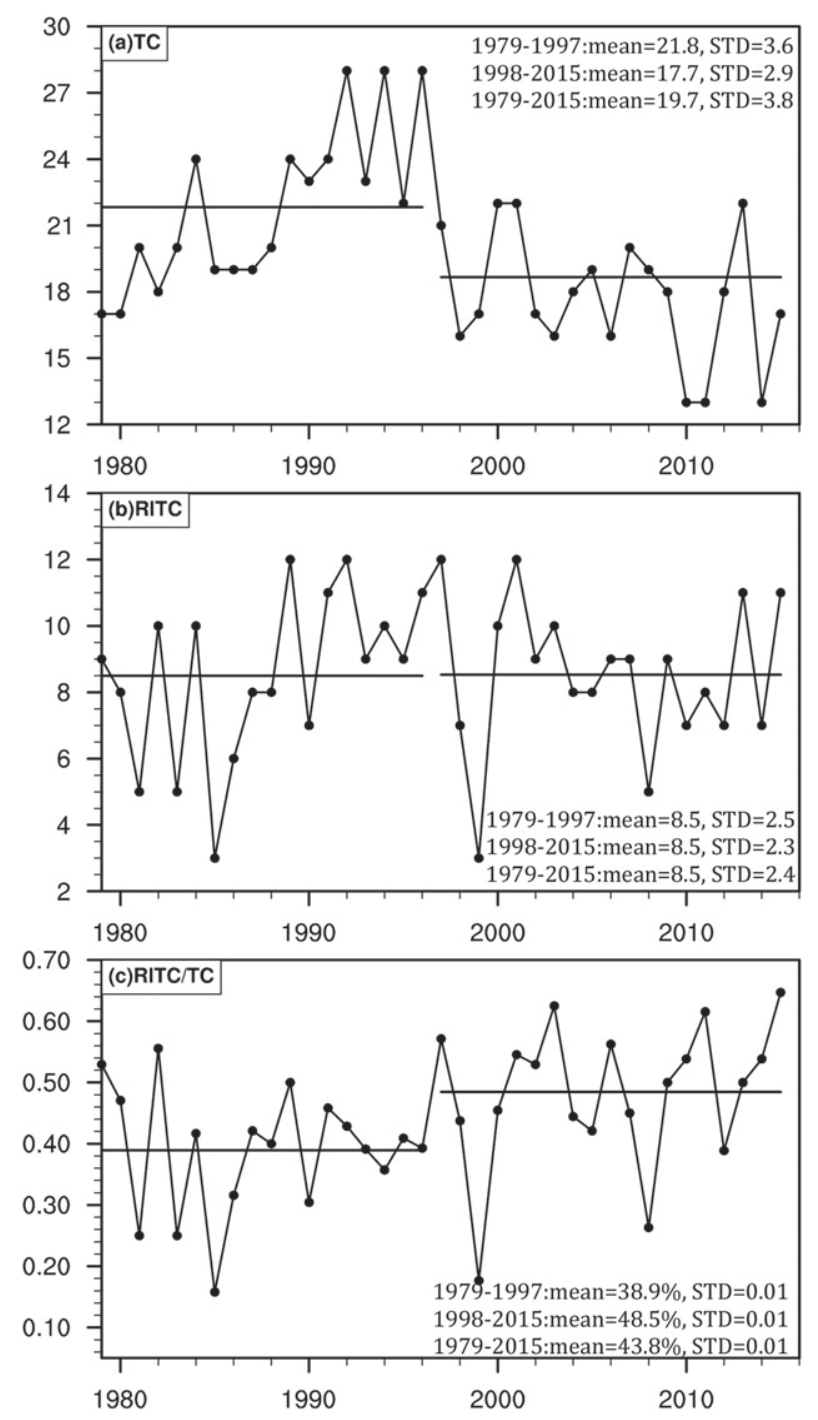

FIG. 2. Time series of (a) TC counts, (b) RITC counts, and (c) proportion of RITCs over the WNP basin during the active season from July to November from 1979 to 2015.

where $C_{p}$ is the specific heat capacity of the seawater at a constant pressure $\left(4178 \mathrm{~J} \mathrm{~kg}^{-1}{ }^{\circ} \mathrm{C}^{-1}\right), D_{26}$ is the depth of the $26^{\circ} \mathrm{C}$ isotherm, $\rho$ is the density of seawater (taken as $1026 \mathrm{~kg} \mathrm{~m}^{-3}$ in the upper ocean), and $T(z)$ is the in situ temperature. TCHP is calculated using the monthly mean oceanic temperature from the Simple Ocean Data Assimilation (SODA), which is based on the Parallel Ocean Program ocean model with a horizontal resolution of $0.5^{\circ} \times 0.5^{\circ}$ in longitude and latitude and 40 vertical layers.

Statistical significance of the composite difference of all variables and their correlations are estimated based on the Student's $t$ test, unless otherwise specified. The $P$ values equal to or less than 0.05 are considered statistically significant in this study. 

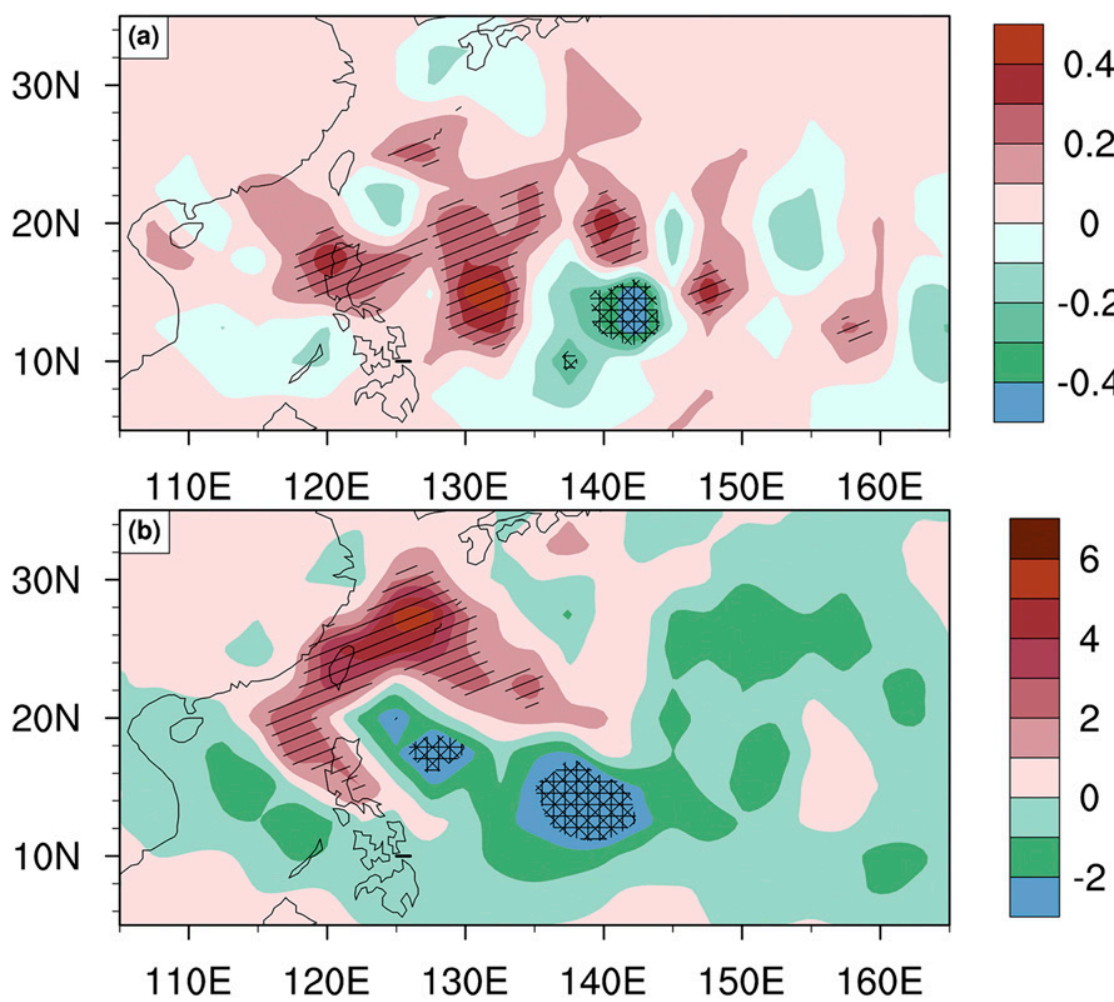

FIG. 3. Composite differences between (a) the two subperiods for RITC occurrence frequency (i.e., 1998-2015 minus 1979-97) and (b) track density for all RITCs. Diagonal hatching and crosshatching represent statistical significance at the $90 \%$ and $95 \%$ confidence levels, respectively.

\section{Recent increase in proportion of RITCs}

\section{a. Decadal change of temporal characteristics}

TC counts from 1979 to 2015 over the WNP basin are shown in Fig. 2a. There has been an average of 19.7 TCs per year with a standard deviation (STD) of 3.8 TCs per year during this period, indicating strong interannual variability. Such interannual variability in TC activity may be associated with ENSO (Wang and Chan 2002; Camargo and Sobel 2005; Zhao et al. 2010, 2011, 2014). In addition to its interannual variability, a significant decadal decrease in TC counts over the WNP basin and weakened interannual variability since 1998 can be seen (Fig. 2a). About 21.8 TCs each year on average occur over the WNP basin with a STD of 3.8 TCs per year during the first subperiod. This contrasts with the second period since 1998, where a significant decrease in TC counts occurred. The second period averaged 17.7 TCs per year with a STD of 2.9 TCs per year. The differences of mean and STD of TC counts respectively are 4.1 and 0.9 between the two subperiods, which both are significant. The significance of the difference of the variance of TC counts between the two subperiods is examined using the $F$ test (Snedecor and Cochran 1989). Such a decadal shift in TC counts was extensively documented in previous studies (Maue 2011; Liu and Chan 2013; Hsu et al. 2014; Zhao and Wang 2016, 2018; He et al. 2017). They largely attributed changes in environmental factors associated with the recent climate regime shift to the significantly decreased TC number over the WNP basin since 1998.

Previous studies (Wang and Zhou 2008; Klotzbach 2012; Shu et al. 2012; Wang and Liu 2016; Wang et al. 2015) have suggested that RI and TC formation generally share common environmental conditions. Associated with the abrupt decrease in TC frequency over the WNP basin during recent decades, it may be natural to speculate that the occurrence of RITCs over the WNP since 1998 should experience a corresponding decrease. Somewhat unexpectedly, RITC frequency over the WNP is nearly unchanged between the two subperiods (Fig. 2b). On an annual average, 8.5 RITCs occurred during both the first and second subperiod.

By definition, changes in the proportion of RITCs depend on the combined changes of TC counts and RITC counts over the WNP basin. The significant decrease in 


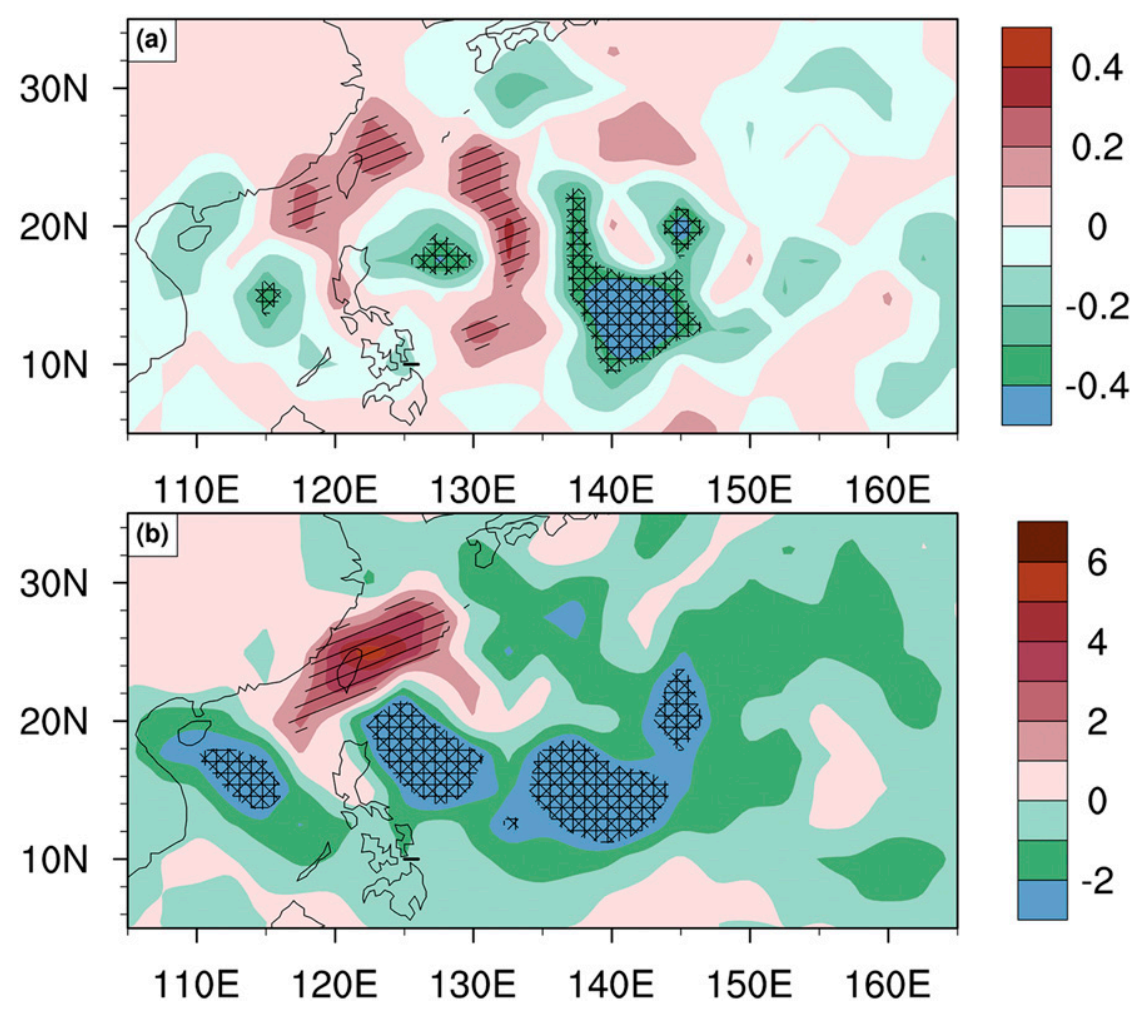

FIG. 4. Composite differences between (a) the two subperiods for TC occurrence frequency (i.e., 1998-2015 minus 1979-97) and (b) track density for all TCs. Diagonal hatching and crosshatching represent statistical significance at the $90 \%$ and $95 \%$ confidence levels, respectively.

TC counts and unchanged RITC frequency during the second subperiod compared to the first subperiod (Figs. 2a and $2 b$ ) consequently results in an increased probability of TCs that develop over the WNP basin undergoing RI. The decadal change in the fraction of RITCs over the WNP basin is clearly displayed in Fig. 2c. The proportion of RITCs over the WNP basin increases by $25 \%$ from the first subperiod to the second subperiod. During the first subperiod, the percentage of RITCs is $38.9 \%$, which is significantly smaller than the percentage of RITCs in the second subperiod $(48.5 \%)$. Additionally, we also used the $42 \mathrm{mb}$ day $^{-1}$ threshold $(1 \mathrm{mb}=1 \mathrm{hPa})$ from Holliday and Thompson (1979) to differentiate storms that intensified even more rapidly (Fig. 1c). A significant increase in the ratio of RITCs over the WNP basin during the recent decades is still observed, with some slight differences in magnitude. During the first subperiod, the percentage of RITCs is $17.1 \%$, which is significantly smaller than the percentage of RITCs in the second subperiod (24.8\%).

\section{b. Decadal change of spatial characteristics}

The spatial distribution of first RI location displays an increase of RITCs over the western WNP, especially west of $135^{\circ} \mathrm{E}$ during $1998-2015$ compared to that during 1979-1997 (Fig. 3a). In contrast, both the southern WNP basin and the South China Sea (SCS) experience a decrease (Fig. 3a). Note that TC formation locations over the WNP show similar decadal changes (Fig. 4a). Generally, an obvious northwestward decadal shift of both TC formation and RI locations during the recent decades can be observed, consistent with results from previous studies (Liu and Chan 2013; Wu et al. 2015; Zhao and Wang 2016; C. D. Hu et al. 2018). Decadal changes in TC tracks for both all TCs and RITCs over the WNP basin are also found. In recent decades, more TCs and RITCs track northwestward, and fewer TCs and RITCs take westward tracks (Figs. $3 b$ and $4 b$ ). Such decadal changes in TC formation location and subsequent track are largely due to changes in environmental factors associated with tropical Pacific decadal variability (Maue 2011; Liu and Chan 2013; Wu et al. 2015; Zhao and Wang 2016, 2018; Zhao et al. 2018; He et al. 2017; Z.-Z. Hu et al. 2017). In fact, a westward retreat of the monsoon trough and a westward shift of the TUTT over the WNP basin during recent decades can be clearly seen (figure not shown), resulting in 
(a)

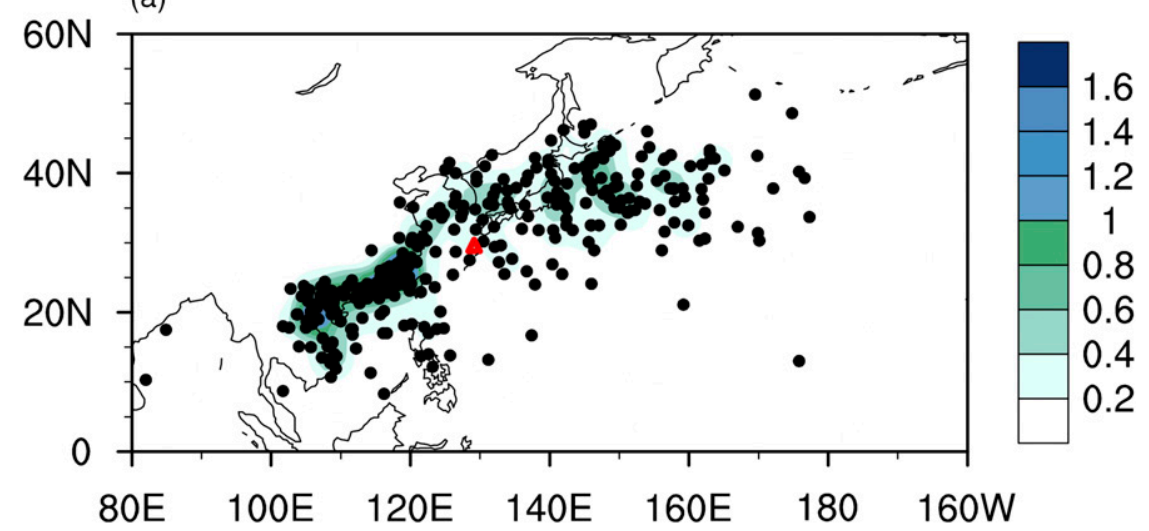

(b)

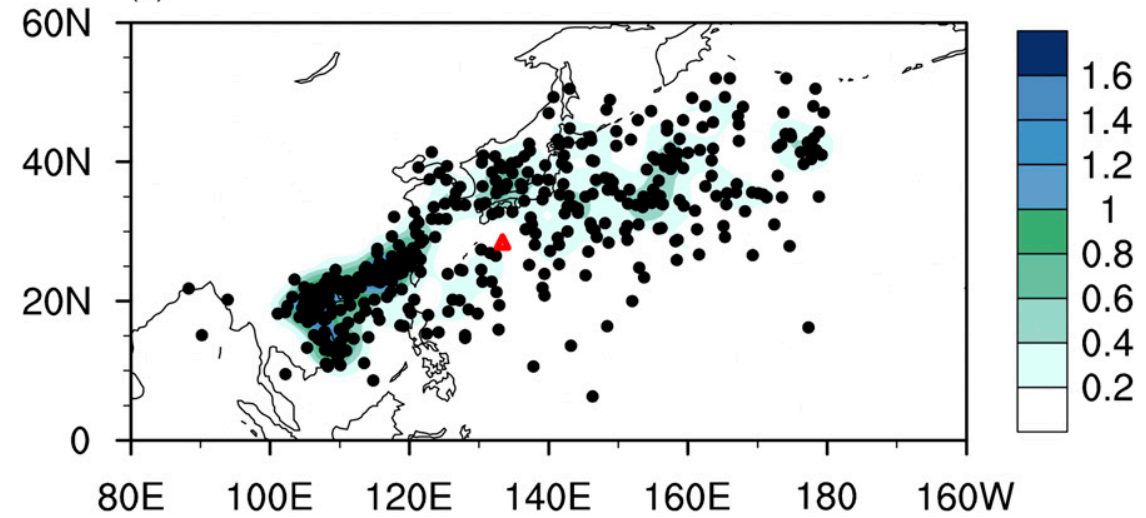

FIG. 5. Locations of lifetime maximum intensity of all TCs during (a) 1998-2015 and (b) 1979-97. Shading represents the annual-mean number of lifetime maximum intensity locations for the two subperiods. The red triangle represents the mean location of peak lifetime intensity.

decreased low-level relative vorticity and increased vertical wind shear, especially over the eastern portion of the WNP basin. Correspondingly, there has been a significant decrease of TC genesis events especially over the southeastern region of the WNP basin during recent decades, which agrees well with a westward shift of TC genesis location over the WNP basin, as suggested by previous studies (Wu et al. 2015; Zhao and Wang 2016, 2018; F. Hu et al. 2018b).

As suggested by Lee et al. (2016), lifetime maximum intensity can be viewed as an integrated TC statistic of RI, and the distinctive bimodality of the lifetime maximum intensity distribution is a fundamental feature of the climate system. They further pointed out that RI is a better criterion for explaining the bimodality of the lifetime maximum intensity. Studies have indicated a significant poleward shift of lifetime maximum intensity over the WNP basin and other regions of the globe (Kossin et al. 2014, 2016). Subsequent studies have indicated that such a poleward shift of peak lifetime intensity is closely associated with the westward shift in
TC formation location (Daloz and Camargo 2018; Zhan and Wang 2017). Indeed, in this study, we find a considerable poleward shift of lifetime peak intensity during the second subperiod (1998-2015) compared to that during the first subperiod (Fig. 5). The averaged location of peak lifetime intensity during the second subperiod and the first subperiod is $29.7^{\circ} \mathrm{N}, 129.9^{\circ} \mathrm{E}$ and $28.3^{\circ} \mathrm{N}$, $132.6^{\circ} \mathrm{E}$, respectively. The differences of averaged latitude $\left(1.4^{\circ}\right)$ and longitude $\left(2.7^{\circ}\right)$ are both statistically significant. Also, the decadal change of spatiotemporal variation of RITCs over the WNP basin including its number, location, and track is generally closely associated with the spatiotemporal changes of TC number, formation location, and TC tracks before and after the climate shift in 1998.

We next investigated RITC counts, TC counts, and the proportion of RITCs at different TC intensity categories (Fig. 6). TCs with different intensity categories experiencing RI between the two subperiods undergo no apparent change (Fig. 6a). In contrast, there is a significant decrease in category-1-2 typhoons and no 

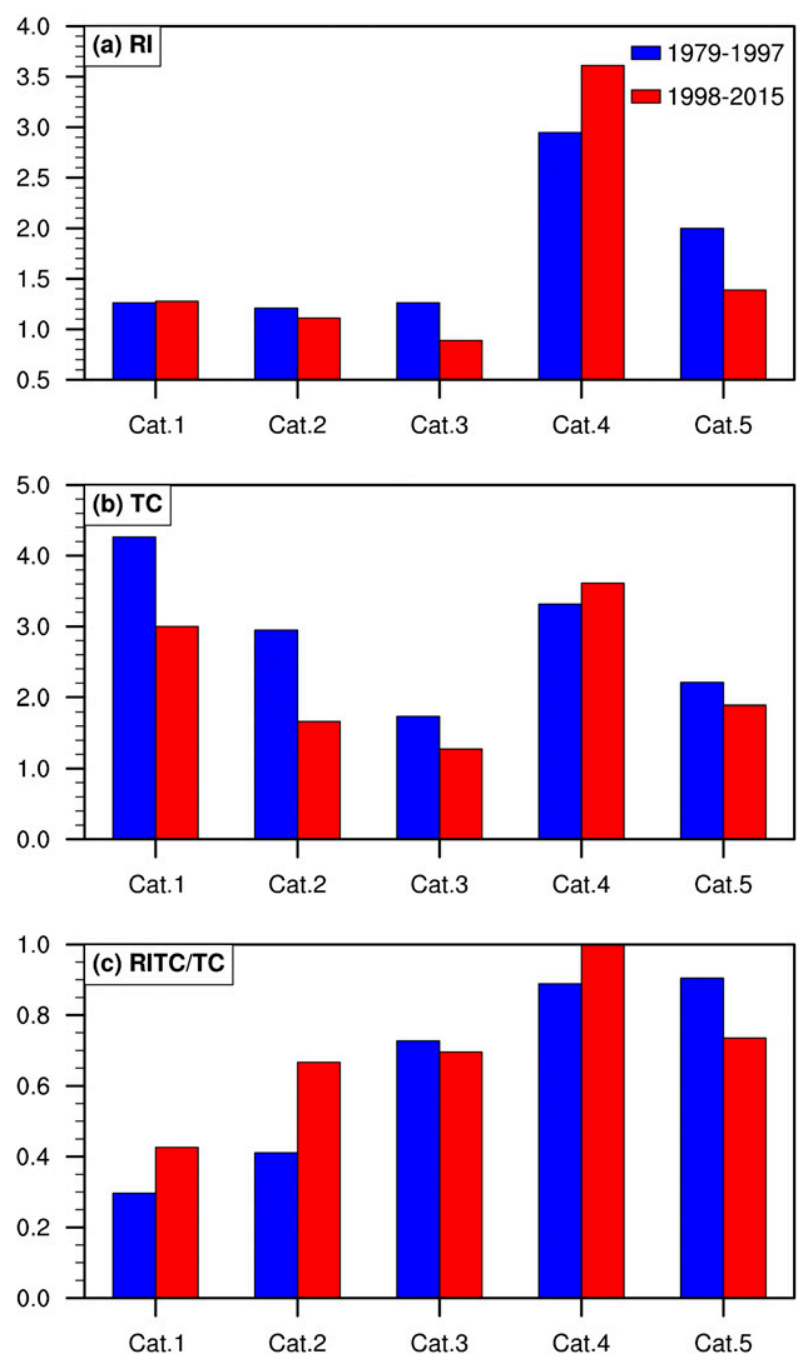

FIG. 6. Occurrence frequency of (a) RITCs, (b) TCs, and (c) proportion of RITCs over the WNP basin during the active season from July to November for two subperiods for different typhoon intensity categories.

significant change in category-3-5 intensity TCs during the second subperiod compared to that during the first subperiod (Fig. 6b). No RI processes were found for TCs in the tropical storm category based on our definition, and thus the number of tropical storms is not shown in Fig. 6b. In fact, the number of TCs of tropical storm category shows little change between the two subperiods. On an annual average, 7.3 and 7.8 tropical storms are observed during the first and second subperiods, respectively. These results indicate that the significant decrease in TC counts over the WNP basin since 1998 is mainly due to a significant decrease in weak typhoons at category-1-2 intensity. Moreover, as shown in Fig. 6c, no obvious change in the ratio of RITCs for category-3-5 TCs is observed, but a significantly
TABLE 1. The proportion (\%) of RITCs over the three regions of the WNP basin for the whole period (1979-2015) and the two subperiods: 1998-2015 (P2) and 1979-97 (P1). Statistical significance is estimated based upon the Student's $t$ test. The asterisk indicates that the difference between the two subperiods is significant at a $95 \%$ confidence level.

\begin{tabular}{lccc}
\hline \hline & $\begin{array}{c}\text { SCS } \\
\left(0^{\circ}-25^{\circ} \mathrm{N},\right. \\
\left.100^{\circ}-120^{\circ} \mathrm{E}\right)\end{array}$ & $\begin{array}{c}\text { WWNP } \\
\left(0^{\circ}-30^{\circ} \mathrm{N},\right. \\
\left.120^{\circ}-135^{\circ} \mathrm{E}\right)\end{array}$ & $\begin{array}{c}\text { EWNP } \\
\left(0^{\circ}-30^{\circ} \mathrm{N},\right. \\
\left.135^{\circ}-180^{\circ} \mathrm{E}\right)\end{array}$ \\
\hline 1979-2015 & 16.1 & 37.8 & 54.8 \\
P2: 1998-2015 & 13.7 & 44.3 & 61.1 \\
P1: 1979-97 & 17.9 & 31.5 & 50.1 \\
P2 minus P1 & -4.2 & $12.8^{*}$ & $11.0^{*}$ \\
\hline
\end{tabular}

increased ratio of RITCs for category-1-2 typhoons can be readily seen. Note that most of these category-1-2 typhoons tend to occur over the western WNP. Zhan et al. (2017) suggested that TCs over the western WNP basin have a greater chance of becoming intense TCs because of a decadal change to a more mega-ENSO state. Therefore, the changes in proportion of RITCs should be to some extent associated with the northwestward shift of TC genesis location and the corresponding changes in environmental conditions.

As shown by both changes in TC formation and first RI location (Figs. 3a and 4a), TC formation locations in the WNP basin can be approximately divided into three regions: SCS $\left(0^{\circ}-25^{\circ} \mathrm{N}, 100^{\circ}-120^{\circ} \mathrm{E}\right)$, western WNP (WWNP) $\left(0^{\circ}-30^{\circ} \mathrm{N}, 120^{\circ}-135^{\circ} \mathrm{E}\right)$, and eastern WNP (EWNP) $\left(0^{\circ}-30^{\circ} \mathrm{N}, 135^{\circ} \mathrm{E}-180^{\circ}\right)$, for examining possible regional differences in the proportion of RITCs. During the whole period from 1979 to 2015, a higher proportion of RITCs can be found over the eastern region of the WNP basin (i.e., EWNP, 55\%) compared to that over the western region of the WNP basin (i.e., WWNP, $38 \%$ ) (Table 1). This agrees well with previous studies of TCs over the eastern WNP, especially over the southeastern region of WNP. These EWNP TCs have a longer duration and consequently have a larger chance for intensification over the warm WNP (Chia and Ropelewski 2002; Wang and Chan 2002; Camargo and Sobel 2005; Camargo et al. 2007; Zhao et al. 2011; Shay et al. 2000; Goni and Trinanes 2003; Lin et al. 2005, 2008, 2009). A comparison of the proportion of RITCs over the three regions of the WNP basin between the two subperiods indicates a significant increase of RITCs over both the EWNP and WWNP during recent decades. During the second subperiod, about $61 \%$ and $44 \%$ of TCs undergo RI in the EWNP and WWNP, respectively, which is significantly larger than $50 \%$ and $32 \%$ over the corresponding regions during the first subperiod (Table 1). In contrast, a moderately decreased ratio of RITCs over the SCS can be observed since 1998. During 1979-97, the proportion of 
TABLE 2. The median and variance of proportion (\%) of RITCs over the three regions of WNP basin for the whole period (1979-2015) and the two subperiods: 1998-2015 (P2) and 1979-97 (P1). Statistical significance of the difference of the median is estimated based upon the Wilcoxon rank sum test and of the difference in the variance is estimated based upon the $F$ test. The asterisk indicates that the difference between the two subperiods is significant at a $95 \%$ confidence level.

\begin{tabular}{|c|c|c|c|c|c|c|}
\hline & \multicolumn{2}{|c|}{$\operatorname{SCS}\left(0^{\circ}-25^{\circ} \mathrm{N}, 100^{\circ}-120^{\circ} \mathrm{E}\right)$} & \multicolumn{2}{|c|}{ WWNP $\left(0^{\circ}-30^{\circ} \mathrm{N}, 120^{\circ}-135^{\circ} \mathrm{E}\right)$} & \multicolumn{2}{|c|}{$\operatorname{EWNP}\left(0^{\circ}-30^{\circ} \mathrm{N}, 135^{\circ} \mathrm{E}-180^{\circ}\right)$} \\
\hline & Median & Variance & Median & Variance & Median & Variance \\
\hline 1979-2015 & 16.7 & 29 & 40 & 25 & 30.8 & 13 \\
\hline P2: 1998-2015 & 8.3 & 20 & 43.6 & 29 & 32.5 & 16 \\
\hline P1: 1979-97 & 20 & 12 & 40 & 4 & 30 & 1 \\
\hline $\mathrm{P} 2$ minus $\mathrm{P} 1$ & $-11.7 *$ & 8 & 3.6 & $25^{*}$ & 2.5 & $15^{*}$ \\
\hline
\end{tabular}

RITCs is $18 \%$ over the SCS, while a lower proportion of RITCs (14\%) is observed during 1998-2015 (Table 1). Although a decrease in the proportion of RITCs over the SCS can be found in recent decades, the difference between the two subperiods is not statistically significant. The significance of differences in the median and variances between the two subperiods was further examined using the Wilcoxon rank sum test and the $F$ test, respectively. As shown in Table 2, the difference of the median in the proportion of RITCs over the SCS between the two subperiods is significant at a $95 \%$ confidence level based upon the Wilcoxon rank sum test, while it is not significant over the WWNP and EWNP subregions. In contrast, the difference of variance of ratio of RITCs over the SCS is not significant at a $95 \%$ confidence level based upon an $F$ test, while enhanced variances over the WWNP and EWNP subregions are significant at a $95 \%$ confidence level. Determining the underlying physical mechanism responsible for these differences is beyond the scope of this study.

Studies have suggested that the change in TC duration is important for intensity change and TC RI (Wang and Chan 2002; Camargo and Sobel 2005; Wang and Zhou 2008; Guo and Tan 2018). The average duration of a TC is about 5.1 days during the period from 1998 to 2015 compared with 5.6 days during the period from 1979 to 1997, in response to the westward shift of mean TC genesis location (Fig. 4a). This appears to be favorable for the recent increase in the ratio of RITCs over the WNP basin. Further examinations are conducted over the three subregions. The decreased proportion of RITCs over the SCS is possibly due to the significant decrease in TC duration, which averaged 6.6 days during the first subperiod and only 3.0 days during the second subperiod (Table 3). The difference of 3.6 days is significant. Over the WWNP and EWNP basin, the difference of the duration for these two regions between the two subperiods is not statistically significant, although the average TC duration shows a slight decrease during the second subperiod compared to the average TC duration during the first subperiod. Moreover, climatologically, the lowest proportion of RITCs among the three regions of the WNP is over the SCS (16\%) (Tables 1 and 3). During the whole period, the average RITC lasts 5.3 days over the SCS, 6.2 days over the WWNP, and 8.2 days over the EWNP (Table 3). We intend to investigate in more detail the impact of TC duration on RI likelihood in future research.

\section{Changes of large-scale atmospheric and oceanic conditions}

To attempt to understand the plausible causes of the significant increase in the percentage of RITCs over the WNP basin during recent decades, we focus on the decadal changes of environmental factors affecting TC activity. Composite differences between the two subperiods of atmospheric factors (e.g., vertical wind shear, low-level relative vorticity, midlevel relative humidity) and oceanic factors (e.g., SST and TCHP) are examined in this section.

Enhanced vertical wind shear and decreased low-level relative vorticity are observed over the WNP basin during recent decades, especially over the southeastern portion of the basin (Figs. 7a and 7b). These are consistent with the significant decrease in TC formation over the WNP basin during recent decades, especially over the southeastern part of the basin. Over the EWNP, 8.6 TCs occurred per year during the second subperiod,

TABLE 3. The averaged lifetime (days) of RITCs over the three regions of the WNP basin for the whole period (1979-2015) and the two subperiods: 1998-2015 (P2) and 1979-97 (P1). Statistical significance is estimated based upon the Student's $t$ test. The asterisk indicates that the difference between the two subperiods is significant at a $95 \%$ confidence level.

\begin{tabular}{lccc}
\hline \hline & $\begin{array}{c}\mathrm{SCS} \\
\left(0^{\circ}-25^{\circ} \mathrm{N},\right. \\
\left.100^{\circ}-120^{\circ} \mathrm{E}\right)\end{array}$ & $\begin{array}{c}\text { WWNP } \\
\left(0^{\circ}-30^{\circ} \mathrm{N},\right. \\
\left.120^{\circ}-135^{\circ} \mathrm{E}\right)\end{array}$ & $\begin{array}{r}\mathrm{EWNP} \\
\left(0^{\circ}-30^{\circ} \mathrm{N},\right. \\
\left.135^{\circ} \mathrm{E}-180^{\circ}\right)\end{array}$ \\
\hline 1979-2015 & 5.3 & 6.2 & 8.2 \\
P2: 1998-2015 & 3.0 & 6.3 & 8.0 \\
P1: 1979-97 & 6.6 & 5.9 & 8.4 \\
P2 minus P1 & $-3.6^{*}$ & 0.4 & -0.4 \\
\hline
\end{tabular}


(a) Vertical Wind Shear

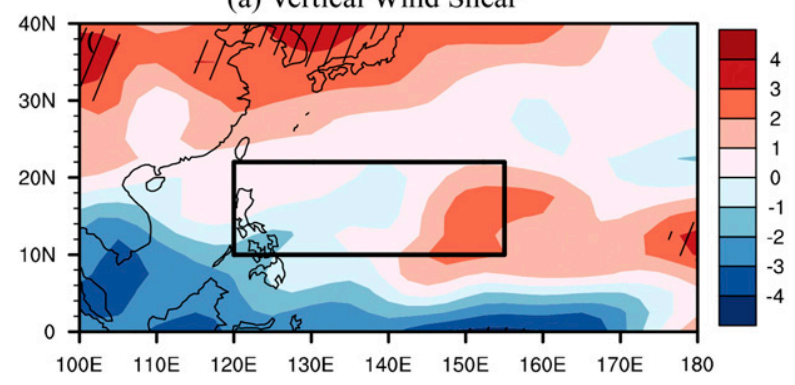

(b) $850 \mathrm{hPa}$ Relative Vorticity

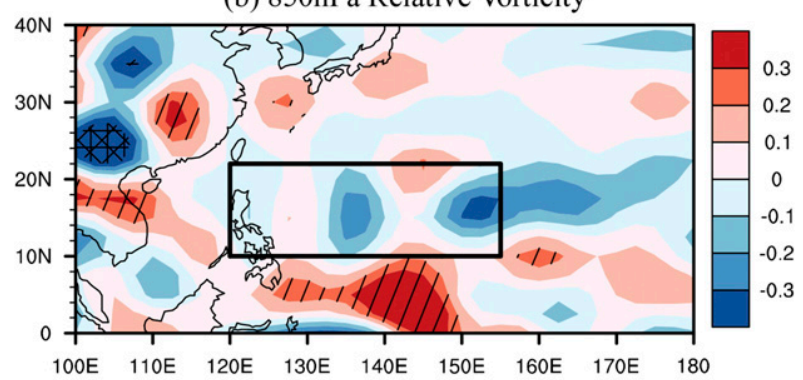

(c) $600 \mathrm{hPa}$ Relative Humidity

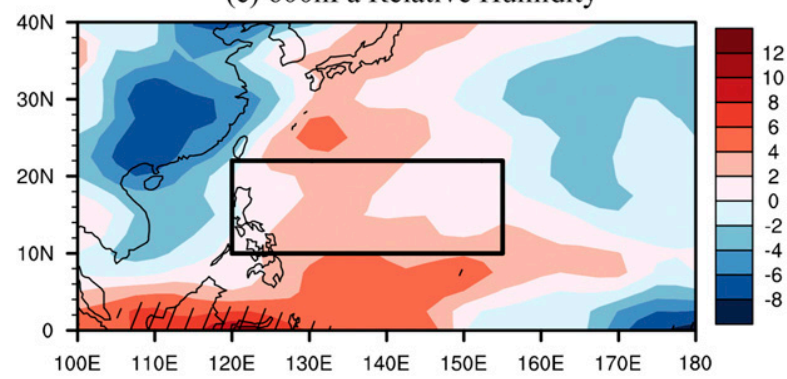

(d) TCHP (Shading)\&SST(Contour)

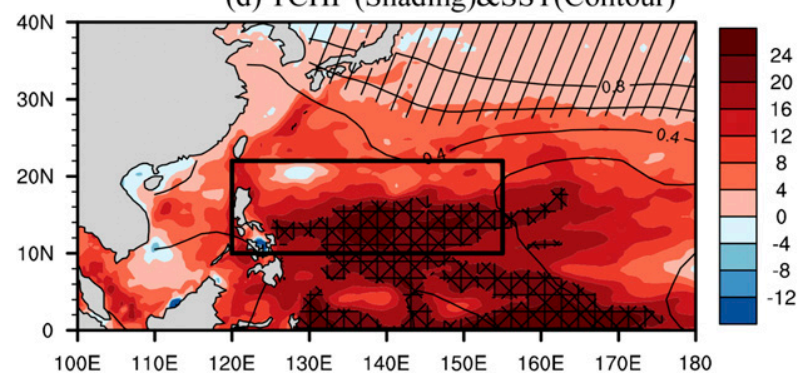

FIG. 7. Composite difference between the two subperiods (19982015 minus 1979-97) for (a) vertical wind shear, (b) 850-hPa relative vorticity, (c) 600-hPa relative humidity, and (d) TCHP (shading) and SST (contours). Diagonal hatching and crosshatching represent statistical significance at the $90 \%$ and $95 \%$ confidence levels, respectively.

which is significantly smaller than the 12.1 TCs per year that occurred during the first subperiod. In contrast, 6.2 TCs on average each year formed over the WWNP during the second subperiod, while 5.9 TCs were observed during the first subperiod. The difference between TC formations in the two subperiods over the WWNP is not significant. As suggested by previous studies on the common environmental conditions for TC genesis and RI (Wang and Zhou 2008; Klotzbach 2012), the recent increased vertical wind shear and decreased 850-hPa relative vorticity appear to be unfavorable for supporting the occurrence of RITCs, especially over the EWNP. The somewhat decreased vertical wind shear over the WWNP plays a role in enhancing RITCs and TCs. However, the midlevel relative humidity shows an increase during the recent decades over almost the whole WNP basin (Fig. 7c), implying that midlevel relative humidity plays a role in contributing to more TCs and RITCs. In summary, the significantly decreased TC counts are largely determined by the two unfavorable atmospheric dynamic factors (i.e., enhanced vertical wind shear and decreased low-level relative vorticity). Meanwhile, the negative impacts of these two atmospheric dynamic factors are partly cancelled out by the positive impact from the midlevel moisture. In contrast, the atmospheric thermodynamic effect (i.e., midlevel moisture) appears to be more conducive for the occurrence of RITCs and thus the intensified proportion of RITCs over the WNP basin since 1998 than the atmospheric dynamic effect (i.e., enhanced vertical wind shear and decreased low-level relative vorticity).

Relative to the impact of atmospheric factors on RITCs, the effect from the oceanic environment appears to be more important (Lin et al. 2008, 2009; Lin and Chan 2015; Wang et al. 2015; Wang and Liu 2016; Wang et al. 2017). Studies have further pointed out that TCs interact not only with the ocean surface but with the upper layer of the ocean (Price 1981; Lin et al. 2003a,b; Sanford et al. 2011; Lin 2012). Therefore, it is very important to examine the oceanic impact on RITCs not only in terms of SST but also in terms of TCHP. Figure 7d depicts differences in the spatial distribution of SST and TCHP over the WNP basin between the two subperiods. SSTA exhibited an increase over the WNP basin, but this increase was not statistically significant. In contrast, the TCHP increased considerably over the WNP basin since 1998, with a significant increase over the main development region for WNP TCs. These seem to present evidence that TCHP is more important than SST for RI, in agreement with previous studies (Shay et al. 2010; Shay 2010). Our calculations indicate that the TCHP exhibits an increase of about $15 \%$ from the first subperiod to the second subperiod, which favors RITCs and thus the ratio of RITCs during the second subperiod. We also find a higher proportion of RITCs over the WNP in the second subperiod. The larger upperocean heat content is typically associated with the presence of large areas of warm water that can effectively limit a cyclone's self-induced negative feedback because of ocean cooling (Lin et al. 2008; Lin and Chan 


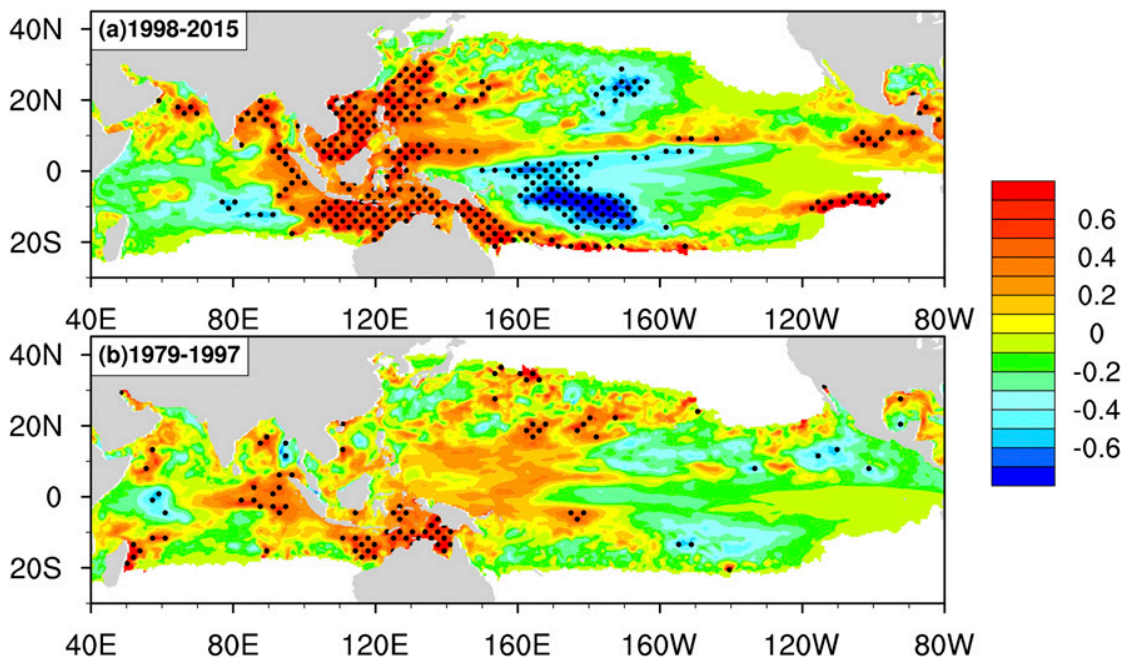

FIG. 8. Correlation pattern of the frequency of RITCs over the WNP basin during the active season from July to November and TCHP for the period during (a) 1998-2015 and (b) 1979-97, respectively. The black dots represent statistical significance at the $95 \%$ confidence level.

2015). The importance of TCHP is further highlighted by the intensified association between TCHP and RITC frequency during the recent decades (Fig. 8). A significant correlation between TCHP and RITC over the WNP is observed during the second subperiod but is not present during the first subperiod.

\section{Associated physical mechanism}

As discussed above, the significant decrease of TC counts over the WNP basin during the recent decades is mainly due to both enhanced vertical wind shear and decreased low-level relative vorticity. In contrast, the frequency of occurrence of RITC remains virtually unchanged during the second subperiod, thus leading to a significant increased proportion of RITCs over the WNP basin, which is largely dependent on more favorable oceanic factors together with increased midlevel moisture.

As suggested by previous studies, significantly different impacts of different SSTA patterns over the WNP have been found (Maue 2011; Liu and Chan 2013; Zhao et al. 2014; Hsu et al. 2014; Zhao and Wang 2016; C. D. Hu et al. 2018; F. Hu et al. 2018a). The pronounced decadal/ interdecadal changes of the SSTA pattern during 19792015 are shown in Fig. 9. Warm SSTAs over the tropical Indo-Pacific region and cool anomalies over the tropical central-eastern Pacific (CEP) are clearly seen during the second subperiod, while an almost opposite pattern is observed during the first subperiod with cooler SSTA over the tropical Indo-Pacific region and warmer SSTA over the tropical central-eastern Pacific. Similar decadal changes in SSTA have also been observed in previous studies
(Weisberg and Wang 1997; Wang et al. 2015; Hsu et al. 2014; F. Hu et al. 2018b).

During recent decades, easterly trade winds have strengthened and a sustained La Niña-like decadal phenomenon has been observed (Fig. 9). Such a strengthening of the large-scale circulation can cause increased vertical wind shear and a weakened monsoon trough over the WNP basin (Figs. 7a and 7b), which impose a strongly negative impact on TC formation over the WNP basin. Additionally, changes in the upper ocean have also been observed (e.g., an increase in the local TCHP). Such an increase is thought to be associated with the recent strengthening of the easterly trade winds, which pile up warm surface ocean water toward the western Pacific. As a result, a thicker layer of warm water accumulates in the WNP basin (Fig. 7d), which plays an important role in enhancing the occurrence of RI over the WNP basin. In contrast, enhanced westerly wind anomalies due to warm SSTA over the CEP basin caused an enhanced monsoon trough and decreased vertical wind shear but also inhibited the build-up of warm surface ocean water in the western Pacific during the first subperiod.

Similar changes to the atmosphere and ocean environment based on Pacific SSTA changes have been demonstrated in previous studies (Hu et al. 2013; Lin and Chan 2015; Hsu et al. 2014; Zhao and Wang 2016; Xiang et al. 2013; Z.-Z. Hu et al. 2017). The strengthening of the atmospheric circulation and increased local TCHP and warm SSTA during the recent decades are closely associated with a tropical Pacific climate shift and shifting ENSO conditions as suggested by previous studies (Z.-Z. Hu et al. 2013, 2017; Zhang et al. 2014; Hsu et al. 2014; Lin and Chan 


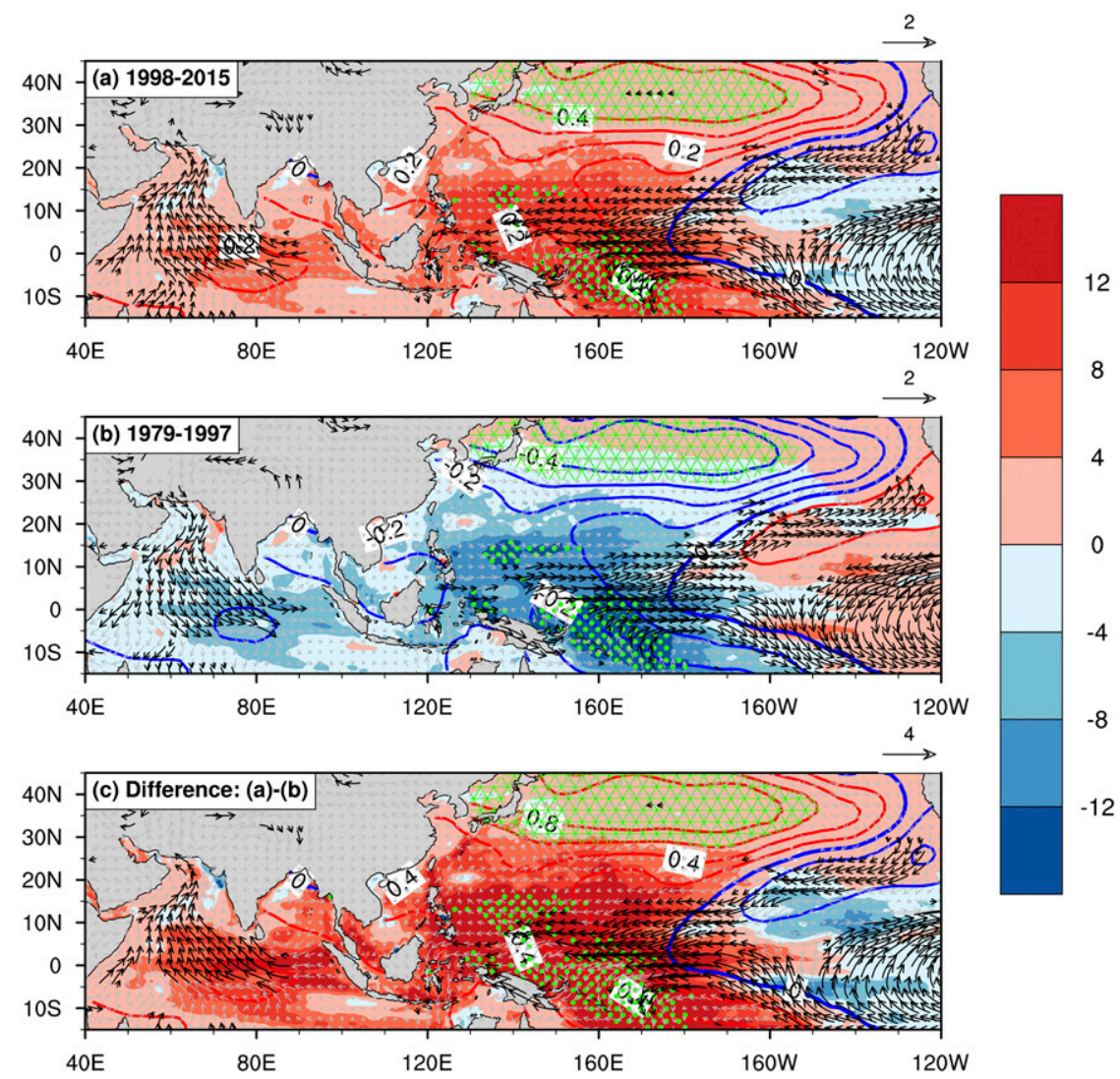

FIG. 9. Composite difference of 850-hPa wind (vectors), SST (contours), and tropical cyclone heat potential (TCHP) (shading) (a) between 1998-2015 and the full time period from 1979 to 2015, (b) between 1979-97 and 1979-2015, and (c) between 1998-2015 and 1979-97, respectively. Crosshatching represents statistical significance at the $95 \%$ confidence level for the SST difference. The black dots represent statistical significance at the $95 \%$ confidence level for the TCHP difference. The vectors in black represent statistical significance at the $95 \%$ confidence level for the 850-hPa wind difference.

2015; Zhao and Wang 2016; C. D. Hu et al. 2018). Additionally, the dominance of local TCHP to the interdecadal modulation of RITCs over the WNP basin is further confirmed by the correlation map between RITC frequency and global TCHP. During the recent decades, an intensified and significant teleconnection between RITC frequency and TCHP over the WNP can be found (Fig. 8). Similar intensified teleconnections during recent decades have been shown in previous studies. These studies suggested that these intensified teleconnections were closely associated with the climate regime shift in 1998 (Zhao et al. 2016; Cao et al. 2016). This presents possible evidence that current changes to the large-scale ocean-atmosphere are closely associated with the recent climate regime shift.

\section{Summary}

A steady and significant improvement in forecasting TC tracks over the past two decades have been achieved, while the prediction of TC intensity, and especially of the RI process, remains a challenge (DeMaria et al. 2014). A well-documented climate shift occurred in 1998, and several studies have highlighted its significant impacts on large-scale factors over the WNP and other regions that consequently affect TC genesis, track, and intensity (C. D. Hu et al. 2018; Zhao and Wang 2016; Wang et al. 2013; Zhang et al. 2014; Xiang et al. 2013; Hu et al. 2013).

In this study we report a significant increase in the proportion of RITCs over the WNP basin during the recent decades compared to the period from 1979 to 1997 (Fig. 2c), which is due to the combined effect of a significant decrease in TC counts and unchanged RITC frequency since 1998 (Figs. 2a and 2b). Analyses of the RITC ratio changes related to TC category and genesis regions suggested that no obvious change in the ratio of RITCs for category-3-5 TCs has been observed, but a significant increased ratio of RITCs for category-1-2 typhoons can be readily seen since 1998 . These are 


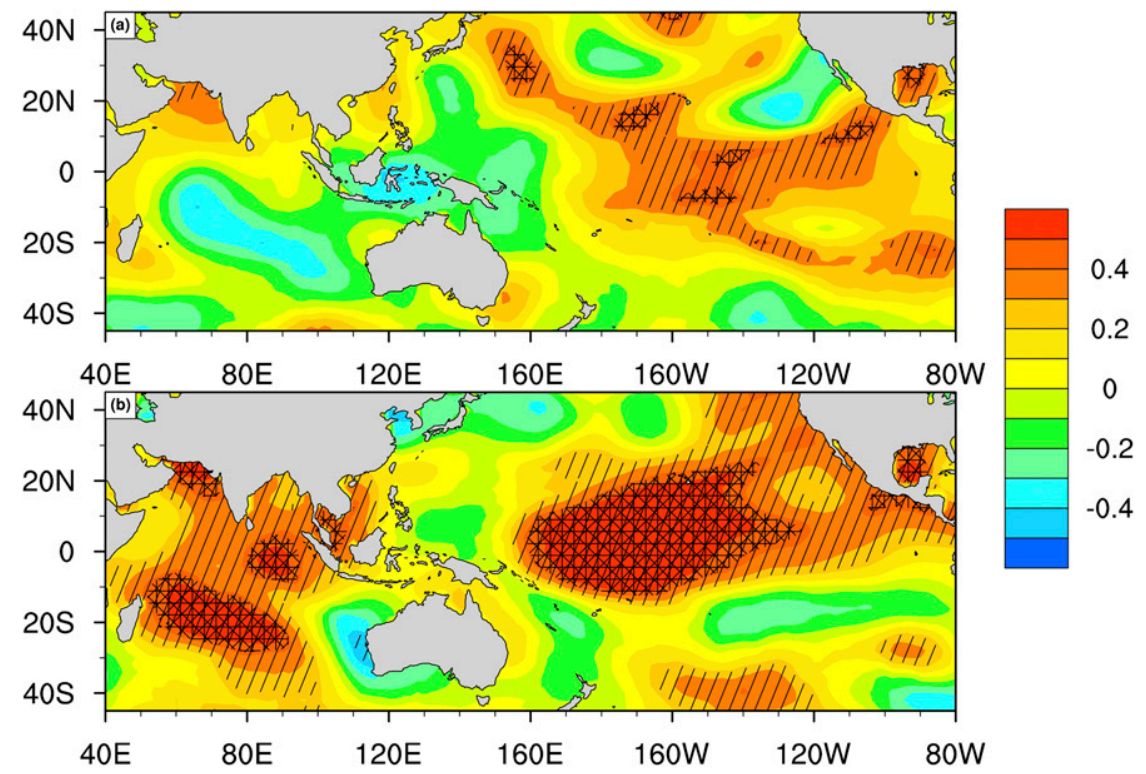

FIG. 10. Correlation pattern of the proportion of RITCs over the WNP basin during the active season from July to November and SST over the Indo-Pacific region for the periods (a) 1998-2015 and (b) 1979-97. Diagonal hatching and crosshatching represent statistical significance at the $90 \%$ and $95 \%$ confidence levels, respectively.

closely related to the changes of TC durations associated with a significant westward shift of TC genesis locations during recent decades. We intend to investigate the impact of TC duration on RI likelihood in future research.

Further analyses show that the decadal changes of TCs and RITCs are largely due to decadal changes of large-scale atmospheric and oceanic factors. Associated with the climate regime shift since 1998, the recent strengthening of the large-scale circulation (Fig. 9) enhances vertical wind shear and weakens the monsoon trough over the WNP, thus inhibiting TC formation and creating an environment unfavorable for RITCs (Figs. 7a and 7b). These stronger easterly trade winds during recent decades (Fig. 9) also contribute to the piling up of warm surface water in the WNP basin, therefore increasing the TCHP (Fig. 7d). The associated increase in midlevel moisture (Fig. 7c) provides a more favorable atmospheric environment for enhanced RITCs, thus increasing the proportion of RITCs over the WNP basin. In summary, during the recent decades the unfavorable atmospheric dynamic conditions have led to a significant decrease of TC genesis over the WNP basin. A more favorable upper-ocean environment plays a key role in the occurrence of RI and thus has increased the ratio of RITCs over the WNP basin in recent decades. Midlevel relative humidity also plays a positive role in supporting RI and the ratio of RITCs over the WNP basin.
This study gives a quantitative analysis of the recent significant increased proportion of RITCs over the WNP through the analysis of decadal change of TCs and RITCs over the WNP basin. The results also indicate an intensified and significant association between the proportion of RITCs over the WNP and tropical SSTA during the recent decades over two regions: the tropical central-eastern Pacific and the tropical Indian Ocean (Fig. 10). Note that in this study we only focus on the possible impacts of the climate shift of 1998 on changes of large-scale factors, while the impact of the recent warm SSTAs in the tropical Indian Ocean and the associated physical process are not discussed. Lee et al. (2015) recently pointed out that Indian Ocean heat content increased abruptly and has accounted for more than $70 \%$ of the global ocean heat gain in the upper ocean during the recent decades. They further indicated that it was mainly due to the strengthening of easterly trade winds over the eastern Pacific during recent decades, leading to the accumulation of warm water in the western Pacific and thus conveying warm water into the Indian Ocean via the Indonesian Throughflow. More recently, Li et al. (2017) suggested that the southeastern Indian Ocean (SEIO) warming was primarily induced by the enhancement of the Pacific trade winds and the Indonesian Throughflow associated with the transition of the interdecadal Pacific oscillation (IPO) to its negative phase, and to a lesser degree by local atmospheric forcing within the Indian Ocean. A significant and 
intensified association between the proportion of RITCs and SEIO SSTAs is readily seen (Fig. 10). Changes in these large-scale factors (e.g., shifting conditions in the tropical Pacific and a warming trend in the tropical Indian Ocean) during recent decades can be found, but their underlying physical mechanisms and the physical processes controlling TC counts and RITCs frequency and thus, the ratio of RITCs over the WNP basin, remains uncertain. These issues deserve further exploration but are beyond the scope of the present study. Finally, we point out that the results of this study based on composite differences and correlation analysis do not necessarily imply causality, and more research using observations and numerical simulations is needed to confirm the underlying mechanisms of the observed changes.

Additionally, we should caution that the results of this manuscript may be influenced by the uncertainty in TC intensity, which needs further investigation with more homogeneous TC records (Emanuel et al. 2018). Moreover, previous studies have suggested a strong impact of the ISO and scale interaction for TCs over the WNP basin by altering the large-scale environment and providing critical precursors for TCs (Hsu et al. 2011; Tsou et al. 2014; Hsu et al. 2017; Weng and Hsu 2017). Given the close association between changes of the proportion of RITCs and the large-scale environment, scale interaction may play an important role in impacting RITCs and the ratio of RITCs over the WNP basin on interdecadal time scales. This topic also deserves further research.

Acknowledgments. This research was jointly supported by the National Natural Science Foundation of China (Grants 41675072,41730961, and 41475091), the Qing Lan Project of Jiangsu Province (R2017Q01), the National Basic Research Program of China (Grant 2015CB452803), and the Priority Academic Program Development of Jiangsu Higher Education Institutions (PAPD). P. Klotzbach would like to acknowledge a grant from the G. Unger Vetlesen Foundation. G. B. Raga acknowledges the support of PASPA-DGAPA during a 6-month sabbatical.

\section{REFERENCES}

Bender, M. A., and I. Ginis, 2000: Real-case simulations of hurricane-ocean interaction using a high-resolution coupled model: Effects on hurricane intensity. Mon. Wea. Rev., 128, 917-946, https://doi.org/10.1175/1520-0493(2000)128<0917: $\mathrm{RCSOHO}>2.0 . \mathrm{CO} ; 2$.

Black, D. E., M. A. Abahazi, R. C. Thunell, A. Kaplan, E. J. Tappa, and L. C. Peterson, 2007: An 8-century tropical Atlantic SST record from the Cariaco Basin: Baseline variability, twentiethcentury warming, and Atlantic hurricane frequency. Paleoceanography, 22, PA4204, https://doi.org/10.1029/2007PA001427.
Brand, S., 1973: Rapid intensification and low-latitude weakening of tropical cyclones of the western North Pacific Ocean. J. Appl. Meteor., 12, 94-103, https://doi.org/10.1175/ 1520-0450(1973)012<0094:RIALLW >2.0.CO;2.

Camargo, S. J., and A. H. Sobel, 2005: Western North Pacific tropical cyclone intensity and ENSO. J. Climate, 18, 29963006, https://doi.org/10.1175/JCLI3457.1.

—, A. W. Robertson, S. J. Gaffney, P. Smyth, and M. Ghil, 2007: Cluster analysis of typhoon tracks. Part II: Large-scale circulation and ENSO. J. Climate, 20, 3654-3676, https://doi.org/ 10.1175/JCLI4203.1.

Cao, X., S. F. Chen, G. H. Chen, and R. G. Wu, 2016: Intensified impact of northern tropical Atlantic SST on tropical cyclogenesis frequency over the western North Pacific after the late 1980s. Adv. Atmos. Sci., 33, 919-930, https://doi.org/10.1007/ s00376-016-5206-z.

Chan, J. C. L., 2008: Decadal variations of intense typhoon occurrence in the western North Pacific. Proc. Roy. Soc. London, 464A, 249-272, https://doi.org/10.1098/rspa.2007.0183.

Chang, C.-P., Y. S. Zhang, and T. Li, 2000a: Interannual and interdecadal variations of the East Asian summer monsoon and tropical Pacific SSTs. Part I: Role of subtropic ridges. J. Climate, 13, 4310-4325, https://doi.org/10.1175/1520-0442(2000)013<4310: IAIVOT $>2.0 . \mathrm{CO} ; 2$.

$\longrightarrow,-$, and,$- 2000 \mathrm{~b}$ : Interannual and interdecadal variations of the East Asian summer monsoon and tropical Pacific SSTs. Part II: Meridional structure of the monsoon. J. Climate, 13, 4326-4340, https://doi.org/10.1175/1520-0442(2000)013<4326: IAIVOT $>2.0 . \mathrm{CO} ; 2$.

Chen, H., D. L. Zhang, J. Carton, and R. Atlas, 2011: On the rapid intensification of Hurricane Wilma (2005). Part I: Model prediction and structural changes. Wea. Forecasting, 26, 885901, https://doi.org/10.1175/WAF-D-11-00001.1.

Chia, H. H., and C. F. Ropelewski, 2002: The interannual variability in the genesis location of tropical cyclones in the northwest Pacific. J. Climate, 15, 2934-2944, https://doi.org/ 10.1175/1520-0442(2002)015<2934:TIVITG > 2.0.CO;2.

Chu, J.-H., C. R. Sampson, A. S. Levine, and E. Fukada, 2002: The Joint Typhoon Warning Center tropical cyclone best tracks 1945-2000. Joint Typhoon Warning Center Rep., Ref. NRL/MR/7540-02-16, Naval Research Laboratory, Washington, DC, http://www.usno.navy.mil/NOOC/nmfc-ph/RSS/ jtwc/best_tracks/TC_bt_report.html.

D'Asaro, E., and Coauthors, 2011: Typhoon-ocean interaction in the western North Pacific, part 1. Oceanography, 24, 24-31, https://doi.org/10.5670/oceanog.2011.91.

Daloz, A. S., and S. J. Camargo, 2018: Is the poleward migration of tropical cyclone maximum intensity associated with a poleward migration of tropical cyclone genesis? Climate Dyn., $\mathbf{5 0}$, 705-715, https://doi.org/10.1007/s00382-017-3636-7.

DeMaria, M., M. Mainelli, L. K. Shay, J. A. Knaff, and J. Kaplan, 2005: Further improvements to the Statistical Hurricane Intensity Prediction Scheme (SHIPS). Wea. Forecasting, 20, 531-543, https://doi.org/10.1175/WAF862.1.

_ C. R. Sampson, J. A. Knaff, and K. D. Musgrave, 2014: Is tropical cyclone intensity guidance improving? Bull. Amer. Meteor. Soc., 95, 387-398, https://doi.org/10.1175/BAMS-D-12-00240.1.

Elsberry, R. L., 2014: Advances in research and forecasting of tropical cyclones from 1963 to 2013. Asia-Pac. J. Atmos. Sci., 50, 3-16, https://doi.org/10.1007/s13143-014-0001-1.

- T. T. D. B. Lambert, and M. A. Boothe, 2007: Accuracy of Atlantic and eastern North Pacific tropical cyclone intensity 
forecast guidance. Wea. Forecasting, 22, 747-762, https:// doi.org/10.1175/WAF1015.1.

Emanuel, K. A., 1986: An air-sea interaction theory for tropical cyclones. Part I: Steady-state maintenance. J. Atmos. Sci., 43, 585-604, https://doi.org/10.1175/1520-0469(1986)043<0585: AASITF $>2.0 . \mathrm{CO} ; 2$.

- 1999: Thermodynamic control of hurricane intensity. Nature, 401, 665-669, https://doi.org/10.1038/44326.

_ 2005: Increasing destructiveness of tropical cyclones over the past 30 years. Nature, 436, 686-688, https://doi.org/10.1038/ nature 03906

_ 2017: Will global warming make hurricane forecasting more difficult? Bull. Amer. Meteor. Soc., 98, 495-501, https://doi.org/ 10.1175/BAMS-D-16-0134.1.

_ - S. Ravela, E. Vivant, and C. Risi, 2006: A statistical deterministic approach to hurricane risk assessment. Bull. Amer. Meteor. Soc., 87, 299-314, https://doi.org/10.1175/ BAMS-87-3-299.

_ - and Coauthors, 2018: On the desirability and feasibility of a global reanalysis of tropical cyclones. Bull. Amer. Meteor. Soc., 99, 427-429, https://doi.org/10.1175/BAMS-D-17-0226.1.

Fitzpatrick, P. J., J. A. Knaff, C.W. Landsea, and S.V. Finley, 1995: Documentation of a systematic bias in the aviation model's forecast of the Atlantic tropical upper-tropospheric trough: Implications for tropical cyclone forecasting. Wea. Forecasting, 10, 433-446, https://doi.org/10.1175/1520-0434(1995)010<0433: DOASBI $>2.0 . \mathrm{CO} ; 2$

Goni, G., and J. A. Trinanes, 2003: Ocean thermal structure monitoring could aid in the intensity forecast of tropical cyclones. Eos, Trans. Amer. Geophys. Union, 84, 573-580, https:// doi.org/10.1029/2003EO510001.

__, and Coauthors, 2009: Applications of satellite-derived ocean measurements to tropical cyclone intensity forecasting. Oceanography, 22, 190-197, https://doi.org/10.5670/ oceanog.2009.78.

Guo, Y.-P., and Z.-M. Tan, 2018: Westward migration of tropical cyclone rapid- intensification over the Northwestern Pacific during short duration El Niño. Nat. Commun., 9, 1507, https:// doi.org/10.1038/s41467-018-03945-y.

He, H. Z., J. Yang, L. G. Wu, D. Y. Gong, B. Wang, and M. N. Gao, 2017: Unusual growth in intense typhoon occurrences over the Philippine Sea in September after the mid-2000s. Climate Dyn., 48, 1893-1910, https://doi.org/10.1007/s00382-016-3181-9.

Holliday, C. R., and A. H. Thompson, 1979: Climatological characteristics of rapidly intensifying typhoons. Mon. Wea. Rev., 107, 1022-1034, https://doi.org/10.1175/1520-0493(1979)107<1022: CCORIT $>2.0 . \mathrm{CO} ; 2$.

Hong, C.-C., T. Li, Y.-K. Wu, and C.-C. Chang, 2014: The climate regime shift over the Pacific during 1996/1997. Climate Dyn., 43, 435-446, https://doi.org/10.1007/s00382-013-1867-9.

_, Y.-K. Wu, and T. Li, 2016: Influence of climate regime shift on the interdecadal change of tropical cyclone activity over Pacific Basin during middle to late 1990s. Climate Dyn., 47, 2587-2600, https://doi.org/10.1007/s00382-016-2986-x.

Hsu, P.-C., T. Li, and C.-H. Tsou, 2011: Interactions between boreal summer intraseasonal oscillations and synoptic-scale disturbances over the western North Pacific. Part I: Energetics diagnosis. J. Climate, 24, 927-941, https://doi.org/ 10.1175/2010JCLI3833.1.

, P. S. Chu, H. Murakami, and X. Zhao, 2014: An abrupt decrease in the late-season typhoon activity over the western North Pacific. J. Climate, 27, 4296-4312, https://doi.org/ 10.1175/JCLI-D-13-00417.1.
, T.-H. Lee, C.-H. Tsou, P.-S. Chu, Y. Qian, and M. Bi, 2017: Role of scale interactions in the abrupt change of tropical cyclone in autumn over the Western North Pacific. Climate Dyn., 49, 3175-3192, https://doi.org/10.1007/s00382-016-3504-x.

Hu, C. D., C.Y. Zhang, S. Yang, D. K. Chen, and S. P. He, 2018: Perspective on the northwestward shift of autumn tropical cyclogenesis locations over the western North Pacific from shifting ENSO. Climate Dyn., https://doi.org/10.1007/ s00382-017-4022-1, in press.

Hu, F., T. Li, J. Liu, M. Bi, and M. Peng, 2018a: Decrease of tropical cyclone genesis frequency in the western North Pacific since 1960s. Dyn. Atmos. Oceans, 81, 42-50, https://doi.org/10.1016/ j.dynatmoce.2017.11.003.

$\longrightarrow, \ldots, \ldots$, and M. Peng, 2018b: Cause of interdecadal change of tropical cyclone controlling parameter in the western North Pacific. Climate Dyn., 51, 719-732, https://doi.org/ 10.1007/s00382-017-3951-z.

Hu, Z.-Z., A. Kumar, H. L. Ren, H. Wang, M. L 'Heureux, and F. Jin, 2013: Weakened interannual variability in the tropical Pacific Ocean since 2000. J. Climate, 26, 2601-2613, https:// doi.org/10.1175/JCLI-D-12-00265.1.

,-- , B. Huang, J. Zhu, and H.-L. Ren, 2017: Interdecadal variations of ENSO around 1999/2000. J. Meteor. Res., 31, 73-81, https://doi.org/10.1007/s13351-017-6074-x.

Huangfu, J., R. Huang, W. Chen, T. Feng, and L. Wu, 2017: Interdecadal variation of tropical cyclone genesis and its relationship to the monsoon trough over the western North Pacific. Int. J. Climatol., 37, 3587-3596, https://doi.org/10.1002/ joc. 4939 .

Kanamitsu, M., W. Ebisuzaki, J. Woollen, S. K. Yang, J. J. Hnilo, M. Fiorino, and G. L. Potter, 2002: NCEP-DOE AMIP-II Reanalysis (R-2). Bull. Amer. Meteor. Soc., 83, 1631-1643, https://doi.org/10.1175/BAMS-83-11-1631.

Kaplan, J., and M. DeMaria, 2003: Large-scale characteristics of rapidly intensifying tropical cyclones in the North Atlantic basin. Wea. Forecasting, 18, 1093-1108, https://doi.org/10.1175/ 1520-0434(2003)018<1093:LCORIT > 2.0.CO;2.

, - - and J. A. Knaff, 2010: A revised tropical cyclone rapid intensification index for the Atlantic and East Pacific basins. Wea. Forecasting, 25, 220-241, https://doi.org/10.1175/ 2009WAF2222280.1.

Kelley, W. E., and D. R. Mock, 1982: A diagnostic study of upper tropospheric cold lows over the western North Pacific. Mon. Wea. Rev., 110, 471-480, https://doi.org/10.1175/ 1520-0493(1982)110<0471:ADSOUT > 2.0.CO;2.

Klotzbach, P. J., 2012: El Niño-Southern Oscillation, the MaddenJulian Oscillation and Atlantic basin tropical cyclone rapid intensification. J. Geophys. Res., 117, D14104, https://doi.org/ 10.1029/2012JD017714.

Knutson, T. R., and Coauthors, 2010: Tropical cyclones and climate change. Nat. Geosci., 3, 157-163, https://doi.org/10.1038/ ngeo779.

Kossin, J. P., K. A. Emanuel, and G. A. Vecchi, 2014: The poleward migration of the location of tropical cyclone maximum intensity. Nature, 509, 349-352, https://doi.org/10.1038/nature13278.

,-- , and -2016 : Comment on 'Roles of interbasin frequency changes in the poleward shifts of the maximum intensity location of tropical cyclones.' Environ. Res. Lett., 11, 068001, https://doi.org/10.1088/1748-9326/11/6/068001.

Lee, C.-Y., M. K. Tippett, A. H. Sobel, and S. J. Camargo, 2016: Rapid intensification and the bimodal distribution of tropical cyclone intensity. Nat. Commun., 7, 10625 , https://doi.org/ 10.1038/ncomms10625. 
Lee, S.-K., W. Park, M. O. Baringer, A. L. Gordon, B. Huber, and Y. Liu, 2015: Pacific origin of the abrupt increase in Indian Ocean heating content during the warming hiatus. Nat. Geosci., 8, 445-450, https://doi.org/10.1038/ngeo2438.

Leipper, D., 1967: Observed ocean conditions and Hurricane Hilda, 1964. J. Atmos. Sci., 24, 182-196, https://doi.org/10.1175/ 1520-0469(1967)024<0182:OOCAHH >2.0.CO;2.

Li, Y. L., W. Q. Han, and L. Zhang, 2017: Enhanced decadal warming of the southeast Indian Ocean during the recent global surface warming slowdown. Geophys. Res. Lett., 44, 9876-9884, https://doi.org/10.1002/2017GL075050.

Lin, I.-I., 2012: Typhoon-induced phytoplankton blooms and primary productivity increase in the western North Pacific subtropical ocean. J. Geophys. Res., 117, C03039, https://doi.org/ 10.1029/2011JC007626.

—_, and J. C. L. Chan, 2015: Recent decrease in typhoon destructive potential and global warming implications. Nat. Commun., 6, 7182, https://doi.org/10.1038/ncomms8182.

—, W. T. Liu, C. C. Wu, J. C. H. Chiang, and C. H. Sui, 2003a: Satellite observations of modulation of surface winds by typhoon-induced upper ocean cooling. Geophys. Res. Lett., 30, 1131, https://doi.org/10.1029/2002GL015674.

— ocean primary production triggered by tropical cyclone. Geophys. Res. Lett., 30, 1718, https://doi.org/10.1029/ 2003 GL017141.

, C. C. Wu, K. Emanuel, I. H. Lee, C. R. Wu, and I. F. Pun, 2005: The interaction of Supertyphoon Maemi (2003) with a warm ocean eddy. Mon. Wea. Rev., 133, 2635-2649, https:// doi.org/10.1175/MWR3005.1.

,-- I. F. Pun, and D. S. Ko, 2008: Upper-ocean thermal structure and the western North Pacific category 5 typhoons. Part I: Ocean features and the category 5 typhoons' intensification. Mon. Wea. Rev., 136, 3288-3306, https://doi.org/ 10.1175/2008MWR2277.1.

- C. H. Chen, I. F. Pun, W. T. Liu, and C. C. Wu, 2009: Warm ocean anomaly, air sea fluxes, and the rapid intensification of tropical cyclone Nargis (2008). Geophys. Res. Lett., 36, 151157, https://doi.org/10.1029/2008GL035815.

— M.-D. Chou, and C.-C. Wu, 2011: Warm ocean eddy's impact on typhoon Morakot (2009) - A preliminary study from remote sensing and numerical modelling. Terr. Atmos. Oceanic Sci., 22, 661-671, https://doi.org/10.3319/TAO.2011.08.19.01(TM).

Liu, K. S., and J. C. L. Chan, 2013: Inactive period of western North Pacific tropical cyclone activity in 1998-2011. J. Climate, 26, 2614-2630, https://doi.org/10.1175/JCLI-D-12-00053.1.

Mainelli, M., M. DeMaria, L. K. Shay, and G. Goni, 2008: Application of oceanic heat content estimation to operational forecasting of recent Atlantic category 5 hurricanes. Wea. Forecasting, 23, 3-16, https://doi.org/10.1175/2007WAF2006111.1.

Maue, R. N., 2011: Recent historically low global tropical cyclone activity. Geophys. Res. Lett., 38, L14803, https://doi.org/ 10.1029/2011GL047711.

McPhaden, M. J., T. Lee, and D. McClurg, 2011: El Niño and its relationship to changing background conditions in the tropical Pacific. Geophys. Res. Lett., 38, L15709, https://doi.org/ 10.1029/2011GL048275.

Miller, A. J., D. R. Cayan, T. P. Barnett, N. E. Graham, and J. M. Oberhuber, 1994: The 1976-77 climate shift of the Pacific Ocean. Oceanography, 7, 21-26, https://doi.org/10.5670/ oceanog.1994.11.

Oey, L. Y., T. Ezer, D.-P. Wang, X.-Q. Yin, and S.-J. Fan, 2007: Hurricane-induced motions and interaction with ocean currents. Cont. Shelf Res., 27, 1249-1263, https://doi.org/ 10.1016/j.csr.2007.01.008.

Pielke, R. A., Jr., J. Gratz, C. W. Landsea, D. Collins, M. A. Saunders, and R. Musulin, 2008: Normalized hurricane damage in the United States: 1900-2005. Nat. Hazards Rev., 9, 29-42, https:// doi.org/10.1061/(ASCE)1527-6988(2008)9:1(29).

Price, J. F., 1981: Upper ocean response to a hurricane. J. Phys. Oceanogr., 11, 153-175, https://doi.org/10.1175/ 1520-0485(1981)011<0153:UORTAH > 2.0.CO;2.

Pun, I. F., Y.-T. Chang, I.-I. Lin, T.-Y. Tang, and R.-C. Lien, 2011: Typhoon-ocean interaction in the Western North Pacific, part 2. Oceanography, 24, 32-41, https://doi.org/10.5670/ oceanog.2011.92.

Rappaport, E. N., and Coauthors, 2009: Advances and challenges at the National Hurricane Center. Wea. Forecasting, 24, 395419, https://doi.org/10.1175/2008WAF2222128.1.

Sanford, T. B., J. F. Price, and J. B. Girton, 2011: Upper-ocean response to Hurricane Frances (2004) observed by profiling EM-APEX floats. J. Phys. Oceanogr., 41, 1041-1056, https:// doi.org/10.1175/2010JPO4313.1.

Shay, L. K., 2010: Air-sea interaction in tropical cyclones. Global Perspectives of Tropical Cyclones, J. C. L. Chan and J. D. Kepert, Eds., World Scientific Publishing Company, 93-132.

- , G. J. Goni, and P. G. Black, 2000: Effects of a warm oceanic feature on Hurricane Opal. Mon. Wea. Rev., 128, 1366-1383, https://doi.org/10.1175/1520-0493(2000)128<1366: EOAWOF $>2.0 . \mathrm{CO} ; 2$

_ , and Coauthors, 2010: Seventh International Workshop on Tropical Cyclones: Air-Sea Interface and Oceanic Influences. IWTC Rep. IWTC-7, St. Gilles Les Bains, La Réunion, France, WMO, http://www.wmo.int/pages/prog/arep/wwrp/tmr/ otherfileformats/IWTCVII-documentation.htm.

Shu, S. J., J. Ming, and P. Chi, 2012: Large-scale characteristics and probability of rapidly intensifying tropical cyclones in the western North Pacific basin. Wea. Forecasting, 27, 411-423, https://doi.org/10.1175/WAF-D-11-00042.1.

Smith, T. M., R. W. Reynolds, T. C. Peterson, and J. Lawrimore, 2008: Improvements to NOAA's historical merged landocean surface temperature analysis (1880-2006). J. Climate, 21, 2283-2296, https://doi.org/10.1175/2007JCLI2100.1.

Snedecor, G. W., and W. G. Cochran, 1989: Statistical Methods. 8th ed. Iowa State University Press, 503 pp.

Soloviev, A. V., R. Lukas, M. A. Donelan, B. K. Haus, and I. Ginis, 2014: The air-sea interface and surface stress under tropical cyclones. Sci. Rep., 4, 5306, https://doi.org/10.1038/srep05306.

Song, J.-J., Y. Wang, and L. Wu, 2010: Trend discrepancies among three best track data sets of western North Pacific tropical cyclones. J. Geophys. Res., 115, D12128, https://doi.org/ 10.1029/2009JD013058.

Tsou, C.-H., H. H. Hsu, and P. C. Hsu, 2014: The role of multiscale interaction in synoptic-scale eddy kinetic energy over the western North Pacific in autumn. J. Climate, 27, 3750-3766, https://doi.org/10.1175/JCLI-D-13-00380.1.

Ventham, J. D., and B. Wang, 2007: Large-scale flow patterns and their influence on the intensification rates of western North Pacific tropical storms. Mon. Wea. Rev., 135, 1110-1127, https://doi.org/10.1175/MWR3327.1.

Wang, B., 1995: Interdecadal changes in El Niño onset in the last four decades. J. Climate, 8, 267-285, https://doi.org/10.1175/ 1520-0442(1995)008<0267:ICIENO>2.0.CO;2.

, and J. C. L. Chan, 2002: How strong ENSO events affect tropical storm activity over the western North Pacific. J. Climate, 
15, 1643-1658, https://doi.org/10.1175/1520-0442(2002)015<1643 HSEEAT $>2.0 . \mathrm{CO} ; 2$.

- and X. Zhou, 2008: Climate variation and prediction of rapid intensification in tropical cyclones in the western North $\mathrm{Pa}$ cific. Meteor. Atmos. Phys., 99, 1-16, https://doi.org/10.1007/ s00703-006-0238-z.

—, J. Liu, H.-J. Kim, P. J. Webster, S.-Y. Yim, and B. Xiang, 2013: Northern Hemisphere summer monsoon intensified by mega-El Niño/southern oscillation and Atlantic multidecadal oscillation. Proc. Natl. Acad. Sci. USA, 110, 5347-5352, https:// doi.org/10.1073/pnas.1219405110.

Wang, C., X. D. Wang, R. H. Weisberg, and M. L. Black, 2017: Variability of tropical cyclone rapid intensification in the North Atlantic and its relationship with climate variations. Climate Dyn., 49, 3627-3645, https://doi.org/10.1007/s00382-017-3537-9.

Wang, X. D., and H. L. Liu, 2016: PDO modulation of ENSO effect on tropical cyclone rapid intensification in the western North Pacific. Climate Dyn., 46, 15-28, https://doi.org/10.1007/ s00382-015-2563-8.

_ C. Wang, L. Zhang, and X. Wang, 2015: Multidecadal variability of tropical cyclone rapid intensification in the western North Pacific. J. Climate, 28, 3806-3820, https://doi.org/ 10.1175/JCLI-D-14-00400.1.

Webster, P. J., G. J. Holland, J. A. Curry, and H. R. Chang, 2005: Changes in tropical cyclone number, duration, and intensity in a warming environment. Science, 309, 1844-1846, https:// doi.org/10.1126/science.1116448.

Weisberg, R., and C. Wang, 1997: A western Pacific oscillator paradigm for the El Niño-Southern Oscillation. Geophys. Res. Lett., 24, 779-782, https://doi.org/10.1029/97GL00689.

Weng, C.-H., and H.-H. Hsu, 2017: Intraseasonal oscillation enhancing C5 typhoon occurrence over the tropical western North Pacific. Geophys. Res. Lett., 44, 3339-3345, https:// doi.org/10.1002/2017GL072743.

Wu, L., and B. Wang, 2008: What has changed the proportion of intense hurricanes in the last 30 years? J. Climate, 21, 14321439, https://doi.org/10.1175/2007JCLI1715.1.

— , and H. Zhao, 2012: Dynamically derived tropical cyclone intensity changes over the western North Pacific. J. Climate, 25, 89-98, https://doi.org/10.1175/2011JCLI4139.1.

_ C. Wang, and B. Wang, 2015: Westward shift of western North Pacific tropical cyclogenesis. Geophys. Res. Lett., 42, 1537-1542, https://doi.org/10.1002/2015GL063450.

Xiang, B., B. Wang, and T. Li, 2013: A new paradigm for the predominance of standing Central Pacific warming after the late 1990s. Climate Dyn., 41, 327-340, https://doi.org/10.1007/ s00382-012-1427-8.

Zhan, R., and Y. Wang, 2017: Weak tropical cyclones dominate the poleward migration of the annual mean location of lifetime maximum intensity of Northwest Pacific tropical cyclones since 1980. J. Climate, 30, 6873-6882, https://doi.org/10.1175/ JCLI-D-17-0019.1.

_ - , and J. Zhao, 2017: Intensified mega-ENSO has increased the proportion of intense tropical cyclones over the western Northwest Pacific since the late 1970s. Geophys. Res. Lett., 44, 11 959-11 966, https://doi.org/10.1002/2017GL075916.

Zhang, Q., Q. Liu, and L. Wu, 2009: Tropical cyclone damages in China 1983-2006. Bull. Amer. Meteor. Soc., 90, 489-495, https://doi.org/10.1175/2008BAMS2631.1.

Zhang, W., F. Jin, and T. Andrew, 2014: Increasing autumn drought over southern China associated with ENSO regime shift. Geophys. Res. Lett., 41, 4020-4026, https://doi.org/10.1002/ 2014GL060130.

Zhao, H., and C. Wang, 2016: Interdecadal modulation on the relationship between ENSO and typhoon activity during the late season in the western North Pacific. Climate Dyn., 47, 315-328, https://doi.org/10.1007/s00382-015-2837-1.

—, and —, 2018: On the relationship between ENSO and tropical cyclones in the western North Pacific during the boreal summer. Climate Dyn., https://doi.org/10.1007/ s00382-018-4136-0, in press.

- L. Wu, and W. Zhou, 2010: Assessing the influence of the ENSO on tropical cyclone prevailing tracks in the western North Pacific. Adv. Atmos. Sci., 27, 1361-1371, https://doi.org/ 10.1007/s00376-010-9161-9.

,-- , and - 2011: Interannual changes of tropical cyclone intensity in the western North Pacific. J. Meteor. Soc. Japan, 89, 243-253, https://doi.org/10.2151/jmsj.2011-305.

, P.-S. Chu, P.-C. Hsu, and H. Muarkami, 2014: Exploratory analysis of extremely low tropical cyclone activity during the late season of 2010 and 1998 over the western North Pacific and the South China Sea. J. Adv. Model. Earth Syst., 6, 11411153, https://doi.org/10.1002/2014MS000381.

_, X. Duan, G. B. Raga, and F. Sun, 2018: Potential large-scale forcing mechanisms driving enhanced North Atlantic tropical cyclone activity since the mid-1990s. J. Climate, 31, 1377-1397, https://doi.org/10.1175/JCLI-D-17-0016.1.

Zhao, J., R. Zhan, Y. Wang, and L. Tao, 2016: Intensified interannual relationship between tropical cyclone genesis frequency over the northwest Pacific and the SST gradient between the Southwest Pacific and the western Pacific warm pool since mid-1970s. J. Climate, 29, 3811-3830, https:// doi.org/10.1175/JCLI-D-15-0729.1.

Zhou, T., and Coauthors, 2009: Why the western Pacific subtropical high has extended westward since the late 1970s. J. Climate, 22, 2199-2215, https://doi.org/10.1175/2008JCLI2527.1. 
